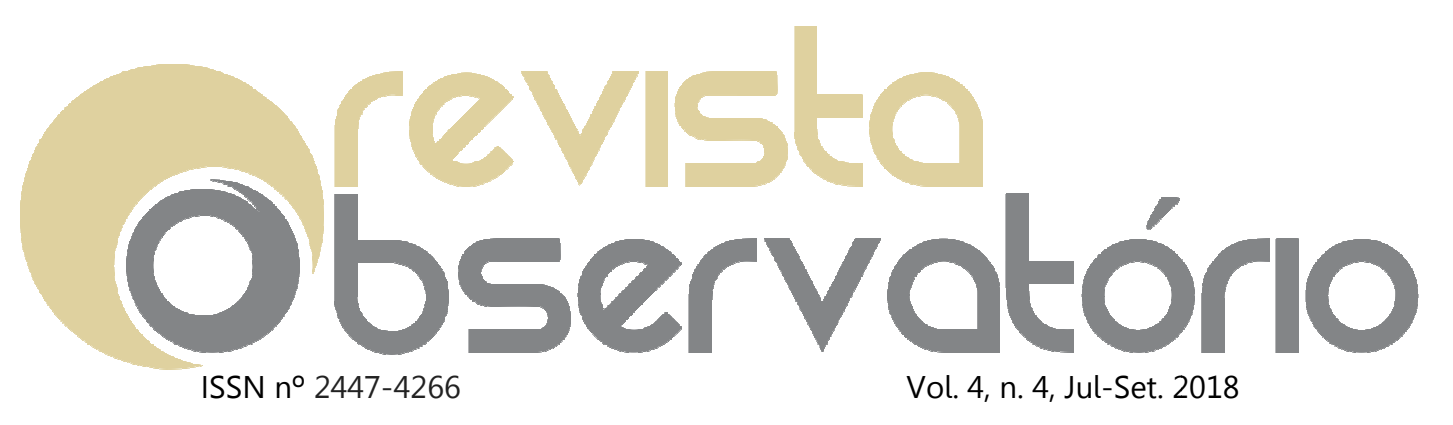

DOI: https://doi.org/10.20873/uft.2447-4266.2018v4n4p46

\section{QUANDO JOGO ATÉ ME ESQUEÇO DAS DORES: \\ Jogos digitais como estratégia para a reabilitação física}

WHEN I PLAY VIDEOGAMES I

FORGET THE PAIN: Videogames

as strategy for physical rehabilitation

CUANDO JUEGO HASTA ME ESCUCHO DE LAS DOLORES:

Videojuegos como estrategia para la rehabilitación física

\author{
Tânia Ribeiro ${ }^{1}$ \\ Ana Isabel Veloso ${ }^{2}$ \\ Liliana Costa ${ }^{3,4}$
}

\title{
RESUMO
}

Não é recente a ideia de recorrer aos jogos digitais como ferramenta de apoio à reabilitação física de pacientes. As causas que afetam a mobilidade física podem ser várias desde Acidentes Vasculares Cerebrais, o envelhecimento ou traumas causados por incidentes. Neste artigo são alvo de análise e discussão jogos digitais e sistemas digitais gamificados que promovem a realização de atividade física como forma de fisioterapia de diversas patologias. $\mathrm{O}$ artigo

\footnotetext{
${ }^{1}$ Mestre em Comunicação Multimédia, Licenciatura em Comunicação e Multimédia, Doutoranda em Informação e Comunicação em Plataformas Digitais na Universidade de Aveiro. E-mail: ribeirotania@ua.pt.

${ }^{2}$ Doutora em Ciências e Tecnologias da Comunicação, Mestre em Enga Biomédica, Licenciada em Enga Informática. Professora auxiliar na Universidade de Aveiro, pesquisadora do Centro de Investigação em Média Digitais e Interação. E-mail: aiv@ua.pt.

${ }^{3}$ Mestre em Comunicação Multimédia, Licenciatura em Comunicação e Multimédia, Doutoranda em Informação e Comunicação em Plataformas Digitais na Universidade de Aveiro, E-mail: lilianavale@ua.pt.

4 Endereço de contato com as autoras (por correio): Universidade de Aveiro. Centro de Investigação em Média Digitais e Interação. Campus Universitário de Santiago, 3810-193 Aveiro, Portugal.
} 


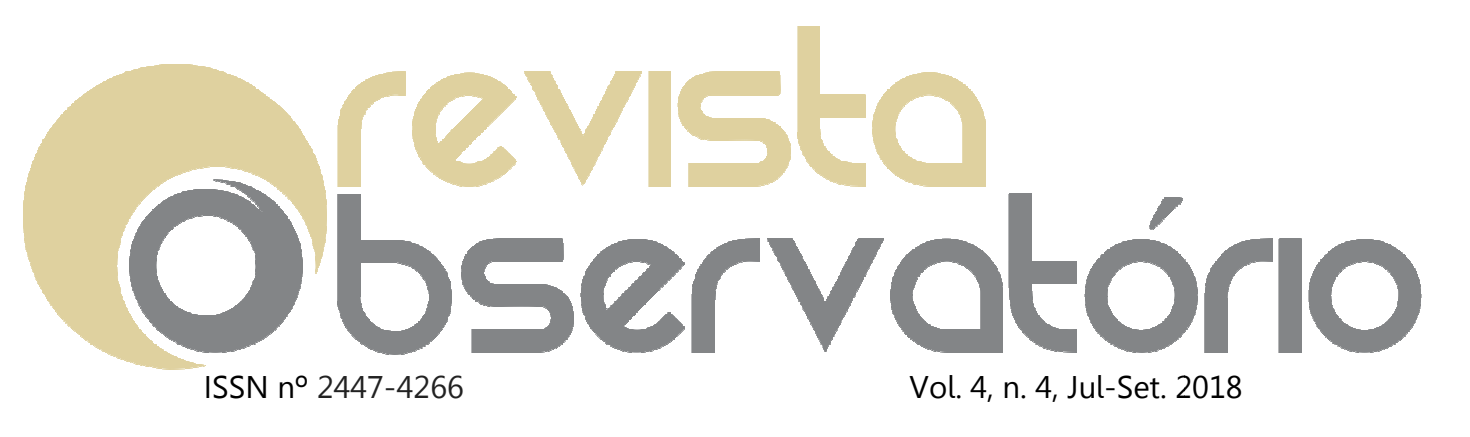

DOI: https://doi.org/10.20873/uft.2447-4266.2018v4n4p46

pretende ainda discutir e enquadrar um conjunto de recomendações que devem ser consideradas no desenvolvimento de jogos digitais desta natureza.

PALAVRAS-CHAVE: Jogos Digitais; Reabilitação física; gamificação; Interação humano-computador.

\begin{abstract}
The idea of using digital games in patients' physical rehabilitation is not new. The causes that affect physical mobility can range from stroke, aging or trauma caused by incidents. In this article, digital games and gamified digital systems that encourage physical activity as a form of physiotherapy of various pathologies are the subject of analysis and discussion. This article aims to discuss and present a set of recommendations that should be considered in the development of such digital games.
\end{abstract}

KEYWORDS: Videogames; Physical rehabilitation; gamification; Humancomputer interaction.

\title{
RESUMEN
}

La idea de utilizar los juegos digitales como una herramienta para apoyar la rehabilitación física de los pacientes no es nueva. Las causas que afectan la movilidad física pueden ir desde accidentes cerebrovasculares, envejecimiento hasta traumatismos causados por incidentes. En este artículo, el objeto de análisis y discusión es los juegos digitales y los sistemas de gamificación que promueven la actividad física como una forma de fisioterapia de diversas patologías. El artículo también tiene la intención de discutir y enmarcar un conjunto de recomendaciones que deben considerarse en el desarrollo de juegos digitales de este tipo. 


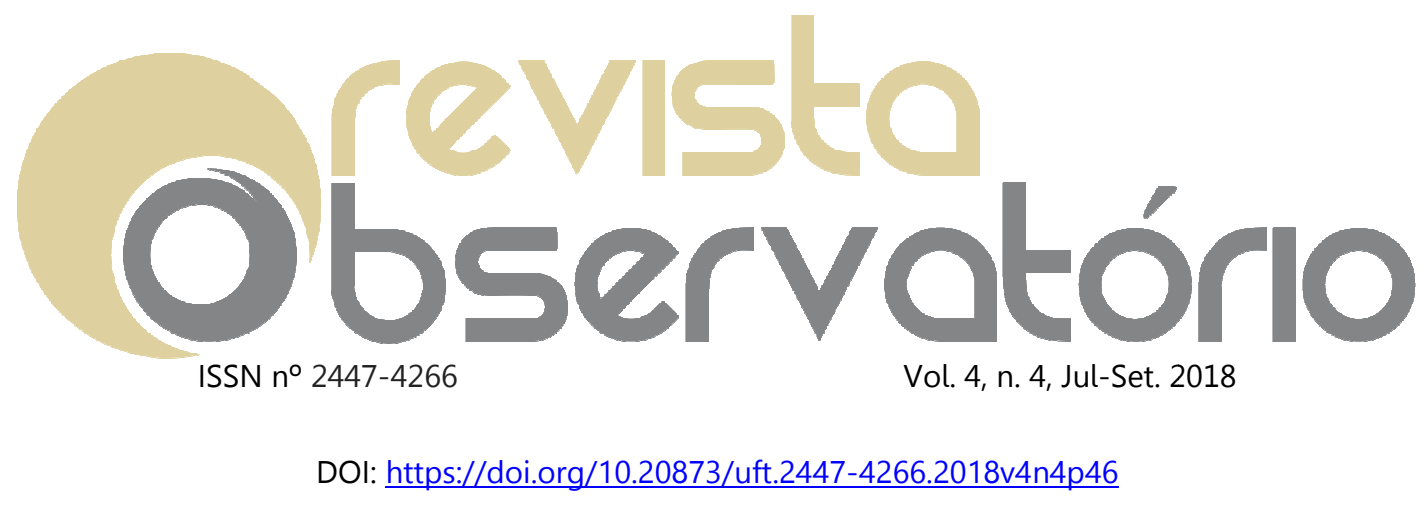

PALABRAS CLAVE: Juegos digitales; Rehabilitación física; gamificación; Interacción humano-computador.

Recebido em: 09.09.2017. Aceito em: 16.12.2017. Publicado em: 29.06.2018. 


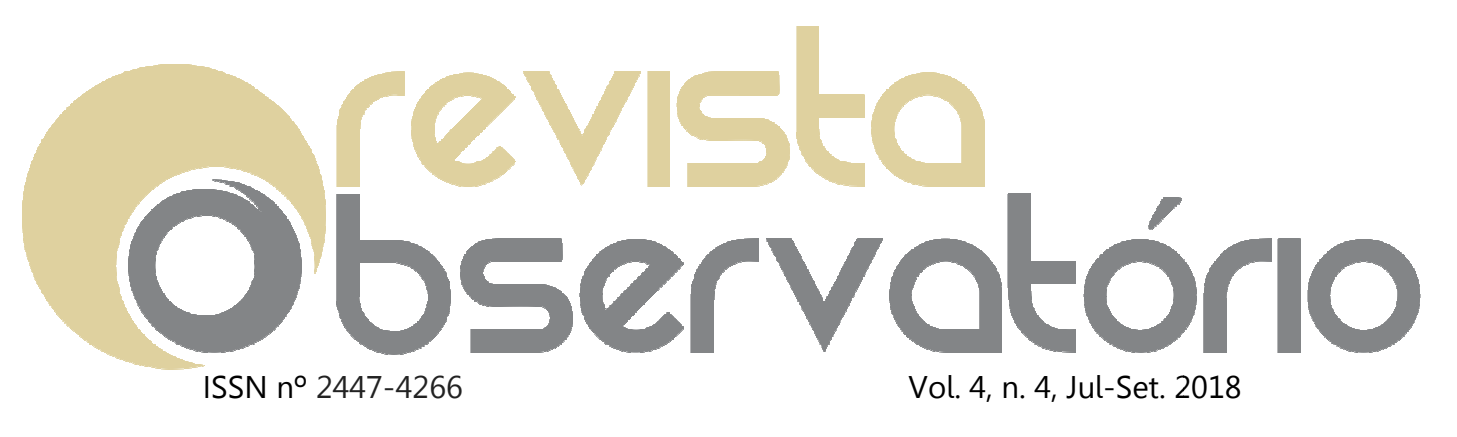

DOI: https://doi.org/10.20873/uft.2447-4266.2018v4n4p46

\section{Introdução}

Os jogos digitais, como forma de reabilitação fisioterapêutica ou terapia ocupacional têm sido utilizados em diferentes grupos de pessoas, desde crianças a seniores (GRIFFITHS, 2005; GRIFFITHS; KUSS; ORTIZ DE GORTARI, 2013).

Como experiência interativa, este artefato tecnológico é capaz de absorver o jogador, desligando-o das preocupações do mundo real e distraindo-o de problemas como o sofrimento físico ou psicológico (GRIFFITHS; KUSS; ORTIZ DE GORTARI, 2013), sendo uma ferramenta com potencial para captar a atenção do jogador por longos períodos de tempo ao suspender a realidade mais imediata (CSIKSZENTMIHALYI, 2008). Para além disso, os jogos digitais permitem aos jogadores viver experiências, novidades e desafios em simultâneo com atividades lúdicas sem consequências na vida real (CRAWFORD, 1984)

Os jogos digitais podem ser vistos como um instrumento terapêutico, uma vez que são capazes de potenciar o aumento do tempo de reação (RIVERO; QUERINO; STARLING-ALVES, 2012), melhoria da autoestima pela superação de desafios e favorecimento da visão espacial devido à manipulação de objetos virtuais (FISHER, 1986; RIVERO; QUERINO; STARLING-ALVES, 2012).

Do ponto de vista teórico, os jogos digitais como ferramenta terapêutica podem ter diversas vantagens, devido à imersão proporcionada em virtude das suas características multimodais interativas e lúdicas (MAYER; MORENO, 2003; RIVERO; QUERINO; STARLING-ALVES, 2012). Estas ferramentas também podem apresentar-se como auxílio em diversos problemas de saúde, por exemplo os pacientes com ansiedade podem ser estimulados de forma a que esta seja controlada e/ou reduzida progressivamente (O'NEIL; GATZIDIS; SWAIN, 2014). 


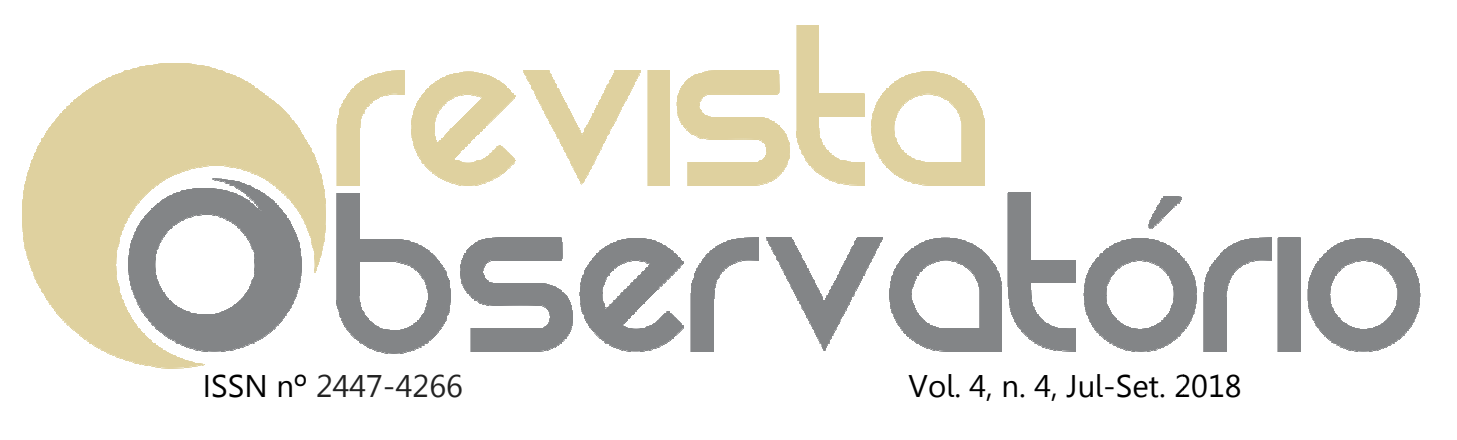

DOI: https://doi.org/10.20873/uft.2447-4266.2018v4n4p46

Os jogos são ferramentas que melhoram a atenção, ajudando na resolução de distúrbios de percepção, podendo contribuir para a melhoria da capacidade de concentração, quando o conteúdo e a narrativa despertam o interesse e a curiosidade do jogador (ADAMS, 2013; FULLERTON, 2008). Os jogos também apresentam características lúdicas que permitem a melhoria da memória e criatividade, contribuindo para o pensamento abstrato, e consequentemente para a superação de distúrbios cognitivos (FISHER, 1986; RIVERO; QUERINO; STARLING-ALVES, 2012).

Do ponto de vista do auxílio na resolução de problemas psicológicos e cognitivos, este médium tem provas dadas, especialmente em jogos cuja interação é baseada em interfaces WIMP (Window, Icon, Menu, Pointing device), ou outro periféricos de manipulação indireta dos objetos de jogo como os joysticks ou comandos (GRIFFITHS, 2005; GRIFFITHS; KUSS; ORTIZ DE GORTARI, 2013).

Atualmente sistemas de interação baseados em gestos já são uma realidade e o uso das "Gestual User Interfaces" nos smarphones e mais tarde nos jogos para o Microsoft Kinect e Leap Motion tornam-se gradualmente mais banais, sendo cada vez mais eficiente interagir com computadores através do movimento do corpo (SAFFER, 2008). Com o surgimento de interfaces emergentes, as Interfaces Cérebro-computador ${ }^{5}$ (STRAIT; SCHEUTZ, 2014), é possível despoletar ações através dos sinais cerebrais.

As secções deste artigo apresentam uma análise do estado-da-arte de jogos e/ou sistemas gamificados cujo intuito seja auxiliar na resolução de problemas físicos ou motores; procuram ainda discutir e enquadrar um conjunto de

\footnotetext{
${ }^{5}$ Em inglês Brain Computer Interface - BCl
} 


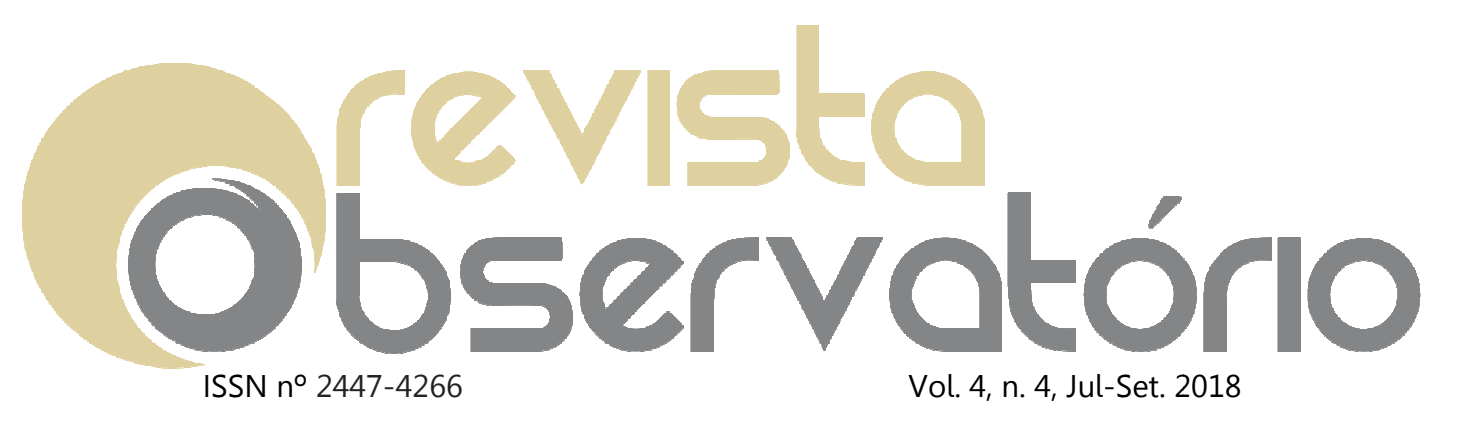

DOI: https://doi.org/10.20873/uft.2447-4266.2018v4n4p46

recomendações que devem ser consideradas no desenvolvimento de jogos digitais e/ou em sistemas digitais gamificadas desta natureza.

Na secção intitulada "Atividade física e Reabilitação física", será apresentado o enquadramento sobre a realidade da atividade física e as consequências da falta da mesma no ser humano; seguido das diferentes patologias que originam problemas físicos graves que comprometem a autonomia do ser humano, e uma contextualização sobre reabilitação física.

Na secção sobre a "História dos Jogos para a reabilitação física" é exposta uma breve contextualização sobre a história dos jogos digitais que vieram sendo disponibilizados em formato comercial, que promovem a atividade física e o movimento. Posteriormente na secção sobre os "Jogos como auxilio da reabilitação de problemas motores", foi realizada uma pesquisa nas bases de dados Scopus e Google Scholar com as palavras chave: jogos digitais, videogames, digital games, gamificação, gamification, reabilitação física e physical rehabilitation. Organizadas no seguinte algoritmo de pesquisa - (jogos digitais OR gamificação OR gamification $\mathrm{OR}$ videogames $\mathrm{OR}$ video games $\mathrm{OR}$ digital games) AND (reabilitação física OR physical rehabilitation) no dia 24 de Agosto de 2017.

Foram considerados para a análise as propostas de jogos ou sistemas digitais gamificados (incentivos de suporte à mudança de comportamento associado a um sistema de pontos, badges, entre outros) que ajudam na recuperação de patologias específicas oriundos do meio académico. Os critérios de exclusão considerados foram os: estudos que analisam o impacto de jogos comerciais já existentes no mercado e concebidos para o público geral; estudos que propunham jogos para a reabilitação física de doenças congénitas, visto que os tratamentos para estas doenças não são direcionados para a 


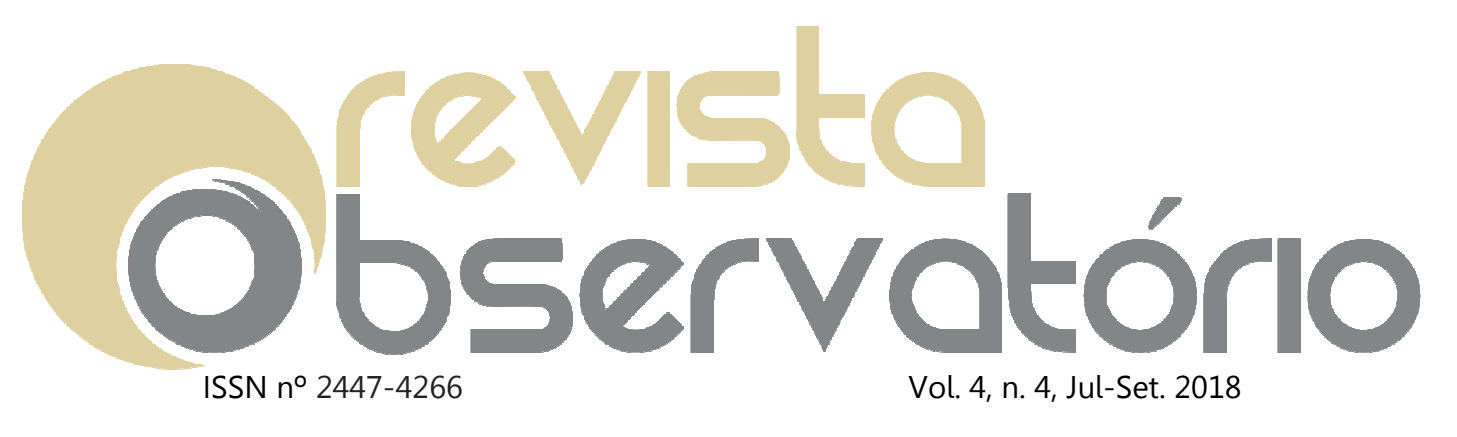

DOI: https://doi.org/10.20873/uft.2447-4266.2018v4n4p46

aprendizagem de novos movimentos e não na reaprendizagem de movimentos perdidos fruto de acidente.

Na secção intitulada "Análise e discussão de dados" é feita uma reflexão crítica e apresenta-se uma proposta de um conjunto de recomendações para o design de jogos digitais direcionados à reabilitação física (FISHER, 1986). O artigo termina com considerações finais e proposta de trabalho futuro.

\section{Atividade física e Reabilitação física}

A Organização Mundial de Saúde (OMS) define atividade física como "qualquer movimento produzido por músculos esqueléticos que requeira gastos de energia". A inatividade física foi identificada pela OMS como o quarto maior risco de morte representando direta ou indiretamente $6 \%$ das mortes a nível mundial (WORLD HEALTH ORGANIZATION, 2017). Para além destes factos, a falta de atividade física está diretamente relacionada com cerca de 21 a $25 \%$ dos cancros da mama e do colón, $27 \%$ dos casos de diabetes e aproximadamente $30 \%$ das doenças cardíacas. O sedentarismo, associado a níveis cada vez mais crescente de quadros de obesidade e diabetes faz com que os problemas cardiovasculares sejam atualmente o problema de saúde mais preocupante nas sociedades ocidentais (GBD 2015 DISEASE AND INJURY INCIDENCE AND PREVALENCE COLLABORATORS, 2016b).

A falta de mobilidade pode despoletar um conjunto de outros problemas no sistema musculoesquelético humano, como a atrofia muscular, lesões na espinal medula, ou problemas associados ao Sistema Nervoso Central (SNC) como o Acidente Vascular Cerebral (AVC), patologias que requerem terapia adequada e especializada (TRUELSEN; BEGG; MATHERS, 2000). 


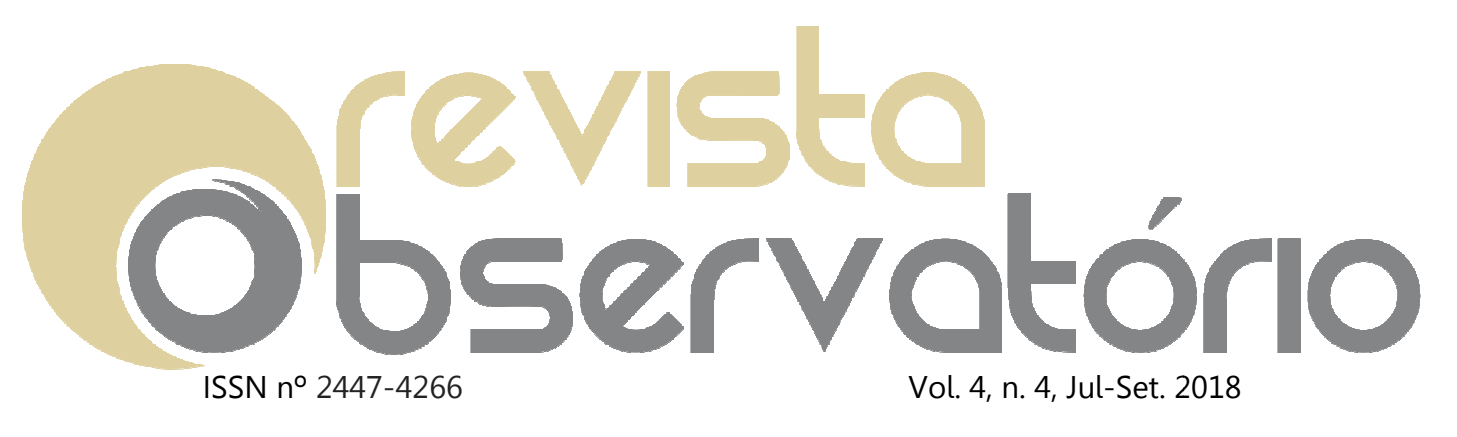

DOI: $\underline{\text { https://doi.org/10.20873/uft.2447-4266.2018v4n4p46 }}$

O objetivo principal da recuperação é melhorar as capacidades funcionais do paciente. A maioria dos processos de tratamento requerem um longo período de tempo, que é tanto maior quanto maior for a gravidade do dano causado pela patologia. E dependente também de fatores como a idade, a condição física do paciente, a morosidade da terapia, a existência de quadros de depressão, e a recuperação porque processos de reabilitação muitas vezes repetitivos podem levar o paciente a perder a motivação e a desistir da terapia. Posto isto é imperativo na sociedade atual usar novas estratégias de motivação para que os pacientes levem a cabo a sua reabilitação com sucesso (LANG et al., 2009).

A reabilitação física clássica através da fisioterapia tradicional, que normalmente é realizada em contexto hospitalar, inclui atualmente uma série de técnicas que na maioria das vezes consistem na repetição de movimentos standard. No contexto clínico, as atividades de repetição podem incluir o supervisionamento de um profissional de saúde, ou a prática dos movimentos com algum objeto, bolas, cones, feijões ou molas de roupa (DICKSTEIN et al., 1986)(DICKSTEIN et al., 1986). Uma vez que o volume de repetições dos movimentos é elevada, no caso de ser um problema físico de origem cerebral, a repetição dos movimentos deve ser na ordem das milhares de repetições (KLEIM; BARBAY; NUDO, 1998). O ideal é que o paciente pratique exercícios em contexto doméstico de uma forma autônoma, mas apesar destas repetições serem previsíveis, sem a supervisão de um cuidador de saúde pode originar movimentos clinicamente incorretos e aprendizagens erradas. Cada situação clínica tem as suas particularidades, no entanto a prática autónoma de fisioterapia nem sempre é realizada pelos doentes e normalmente está 


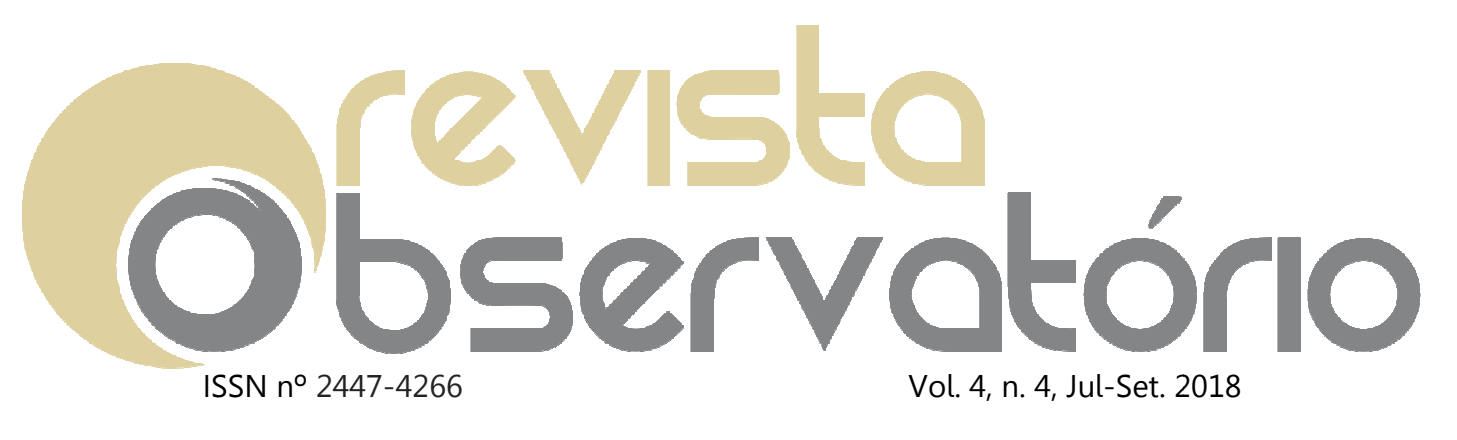

DOI: https://doi.org/10.20873/uft.2447-4266.2018v4n4p46

associada à falta de motivação devido a atividades monótonas e pouco motivadoras, como a simulação de tarefas domésticas (O'NEIL; GATZIDIS; SWAIN, 2014).

No caso de um portador de doença é importantíssimo manter a pessoa motivada para a terapia, evitando níveis altos de stress e quadros depressivos, uma vez que estas condições podem por em causa uma completa recuperação, ou dar origem a reaprendizagens de movimentos físicos errados, que podem originar problemas motores em cascata (GRIFFITHS, 2005).

\section{História dos jogos de interação física}

Os jogos digitais e as simulações por computador têm sido reconhecidas como ferramentas motivacionais na reabilitação, por exemplo na neuroreabilitação e na fisioterapia, mas a ideia de usar equipamento de exercício como interface para jogos digitais é quase tão antiga como a história dos jogos digitais no seu formato comercial (SINCLAIR; HINGSTON; MASEK, 2007).

A primeira tentativa de implementação de um jogo digital para a atividade física surge em 1982 com o Atari Puffer Project, um projeto motivado pelo facto de na América existirem demasiadas crianças (e adultos) sedentários e obesos. O protótipo consistia na junção de uma bicicleta de fitness conectada a uma consola. O projeto nunca viu um lançamento comercial devido a questões internas da empresa (YANG, 2010). Não obstante, em 1983, é lançado um joystick para bicicletas de fitness cuja ideia era, quanto mais depressa o jogador pedalasse, mais depressa se movia o seu Avatar no ambiente de jogo. O joystick, conectado à bicicleta, servia para guiar a personagem no cenário (ATARI, 2002). 


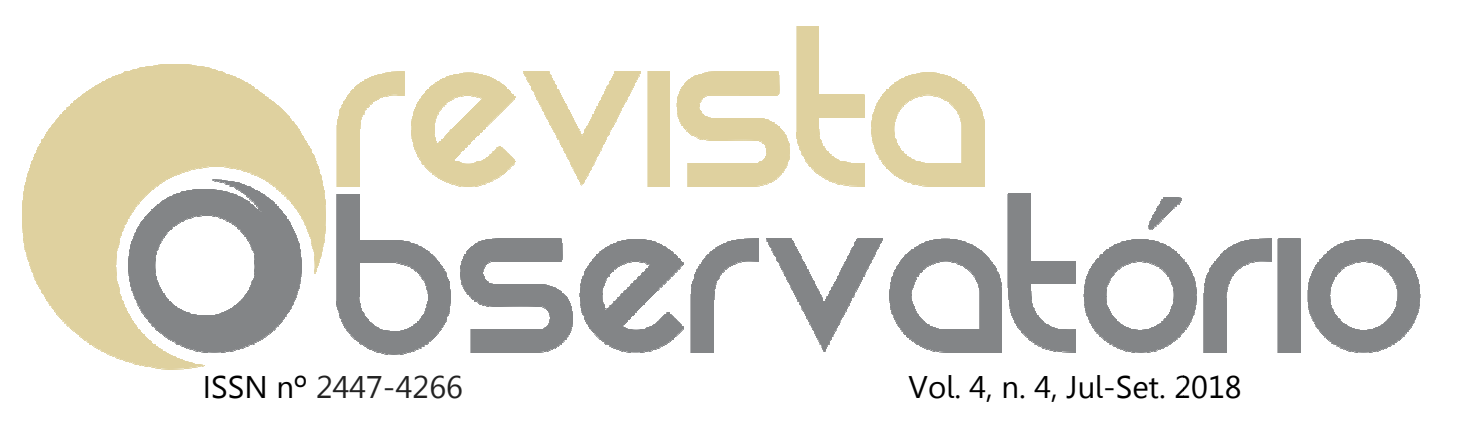

DOI: $\underline{\text { https://doi.org/10.20873/uft.2447-4266.2018v4n4p46 }}$

Ao longo da história dos jogos digitais, outros exemplos foram surgindo. No final dos anos 80, a empresa Autodesk lança o HighCicle, um jogo com uma bicicleta fixa a servir de controlador (SINCLAIR; HINGSTON; MASEK, 2007). Nos anos 80 , surge também um novo paradigma de interação, os foot operated pads, que simplificadamente eram tapetes com uma série de sensores incorporados, capazes de detectar o toque do pé do jogador.

Devido a avanços tecnológicos em sensores e atuadores, e ao sucesso que estes jogos iam tendo no mercado, uma série de empresas lançaram jogos para a atividade física. Em 1987, a Nintendo lança o Power Pad e, em 1988, é lançado o Dance Dance Revolution (DDR) pela Konami, um produto muito semelhante ao Power Pad da Nintendo. No écran, era mostrada uma série de passos de dança que o jogador deveria copiar, fazendo corresponder os passos à música que tocava. O DDR foi um enorme sucesso comercial pelo divertimento proporcionado, com cerca de 6.5 milhões de vendas (NIIZUMI, 2003).

Mais recentemente, em 2006, a Nintendo lança a Nintendo Wii, com o Wii Controller. Este controlador traz embutido uma série de sensores de movimento mais precisos (i.e., acelerómetro e giroscópio) que possibilitam, ao sistema de jogo, detectar as ações e a posição relativa do comando no espaço. Para esta plataforma foi lançada uma série de jogos relacionados com a prática desportiva (e.g., ténis, basebol, bowling, golfe e boxe). O sistema Wii aumentou o debate e interesse na área dos jogos digitais para a atividade física, pelo facto de ficar provado comercialmente que, por um lado, o público geral tem interesse neste tipo de jogos (YANG, 2010), por outro verificou-se que a tecnologia ligada à monitorização de movimento estava suficientemente maturada para uma apropriação efetiva (DEUTSCH et al., 2015). 


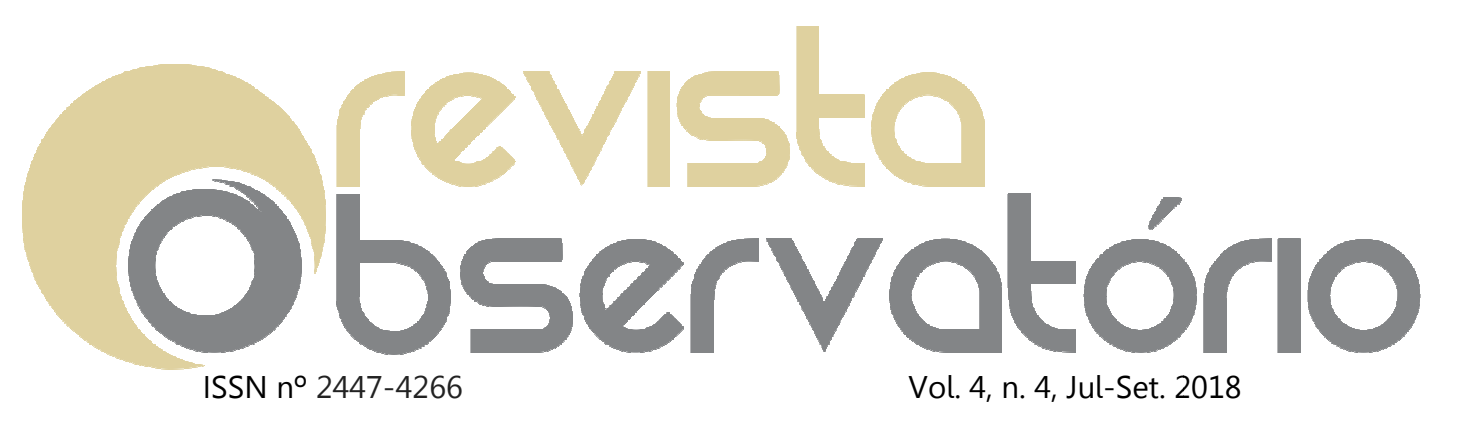

DOI: $\underline{\text { https://doi.org/10.20873/uft.2447-4266.2018v4n4p46 }}$

Hoje em dia, para além da Nintendo Wii, o Microsoft Kinect (que vai na segunda edição) e o sensor Leap Motion, apresentam-se como controladores capazes de monitorizar o movimento do jogador com uma presença sólida no mercado. Paralelamente, com a democratização e a convergência tecnológica, hoje em dia, os sensores e atuadores estão cada vez mais pequenos e com custos mais acessíveis, tornando possível a apropriação tecnológica e a proposta de novas formas de interação.

Muitos estudos (BAINBRIDGE et al., 2011) têm sugerido a utilização de jogos digitais comerciais no auxílio do tratamento de doenças físicas, desde jogos para a plataforma Wii como estratégia de reabilitação de doentes em unidades de cuidados intensivos ou com Parkinson (KHO et al., 2012), a jogos para a PlayStation para ajudar doentes com paralisia cerebral (BONNECHÈRE et al., 2016). Contudo, a singularidade de cada patologia leva a tratamentos específicos de acordo com a patologia que se quer ver tratada, o que implica o design de jogos adequados e personalizados tendo em conta o paciente e $\mathrm{o}$ seu quadro clínico.

\section{Jogos como auxílio da reabilitação de problemas motores}

Esta secção enumera e descreve alguns jogos digitais utilizados como estratégia para a reabilitação física. Os jogos enumerados obedecem às seguintes características: têm o objetivo de ajudar na recuperação física ou de mobilidade; a patologia alvo da terapia não é uma doença congénita; os artigos onde são descritos são suficientemente explicativos no que diz respeito às regras, objetivos, narrativa e tecnologia usada. 


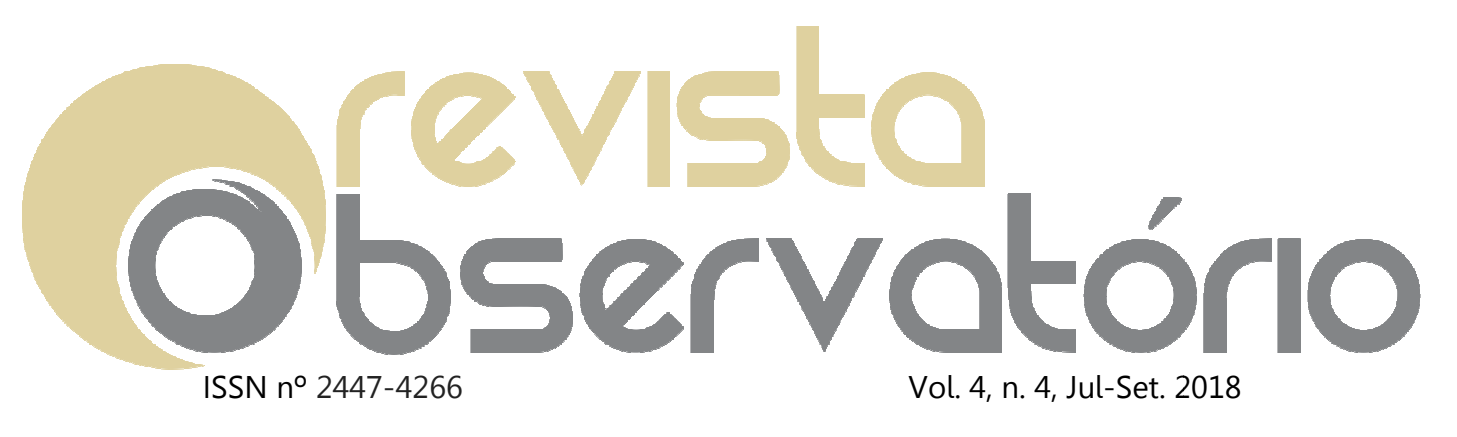

DOI: https://doi.org/10.20873/uft.2447-4266.2018v4n4p46

MoU-Rehab - Jogo mobile que providencia treino intensivo baseado na repetição de movimentos, recorrendo à digitalização de movimentos usados em contexto clinico usados para auxiliar no tratamento dos músculos espásticos do membro superior em doentes vítima de AVC. O jogo tem o total de 4 níveis, cada nível correspondente a um movimento fisioterapêutico. No primeiro nível, o jogador é o "Guardião" de um pote de mel e cada vez que uma abelha se aproxima do pote o jogador deve fletir o cotovelo para matar a abelha. No segundo nível, o jogador tem de alimentar coelhos através de movimentos de abdução e adução do ombro. No terceiro nível, o jogador deve apagar um fogo através de movimentos de abdução, adução, flexão e extensão do ombro. No quarto e último nível, o jogador deve regar uma planta executando os mesmos movimentos que no nível anterior, acrescidos de propanação e supinação do pulso. Para jogar, é necessário um smartphone e um tablet. O smartphone, acoplado ao braço, monitoriza e processa os movimentos executados pelo jogador que são enviados para o tablet, dispositivo onde o jogador visualiza o terreno do jogo e recebe feedback das suas ações.

O jogo foi testado recorrendo a uma amostra de 24 pacientes (em regime hospitalar), onde metade deles serviu de grupo de controlo, executando apenas os movimentos fisioterapêuticos de forma tradicional. $O$ grupo que recebeu o jogo, mostrou avanços na terapia no que diz respeito na eficácia na performance dos movimentos fisioterapêuticos (CHOl et al., 2016).

ARMStrokes - Aplicação mobile que fornece suporte ao tratamento dos membros superiores afetados em doentes vítimas de AVC em contexto doméstico. A aplicação tem dois jogos, o "Monkey George" e o "Little Astronaut". O objetivo do primeiro jogo é ajudar a personagem, um macaco, a 


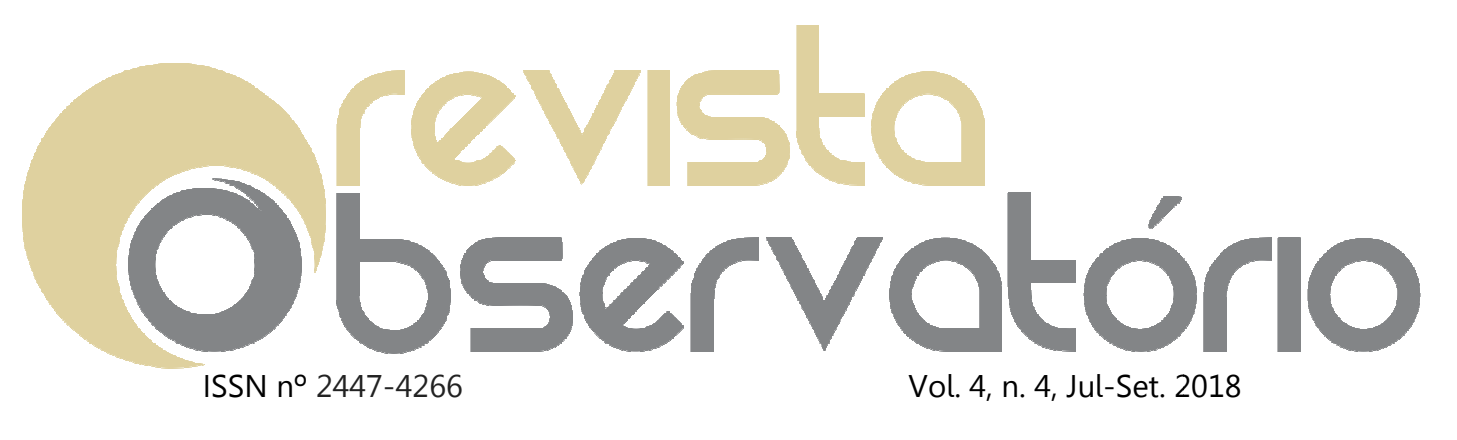

DOI: https://doi.org/10.20873/uft.2447-4266.2018v4n4p46

subir a árvores e procurar bananas. No segundo jogo, o jogador assume o papel de um astronauta em exploração espacial. À semelhança de MoU-Rehab, os gestos requeridos no jogo são uma digitalização de movimentos fisioterapêuticos usados em contexto clinico. Os jogos foram desenvolvidos para iOS, sendo que o utilizador apenas necessita de um smartphone para jogar e faz uso de um sistema de comunicação integrado que reporta os avanços e recuos a um provedor de saúde. O sistema foi avaliado com 15 pacientes e 5 provedores de saúde (4 fisioterapeutas e 1 fisiatra). Todos os pacientes concordaram que o sistema fornece um bom apoio para o contexto doméstico (TANG et al., 2015).

Hand-rehab-Jogo que recorre a exercícios utilizados em clínicas de fisioterapia para reabilitação da mão afetada em doentes vítimas de AVC. O exercício consiste em empilhar cones e deslocá-los em cima de uma superfície plana. $\mathrm{Na}$ proposta, em vez de uma mesa, é utilizado um ecrã touchscreen disposto na horizontal e, em vez de cones, o sistema propõe diferentes objetos com diferentes formas e com peso personalizável pelo provedor de saúde. O jogador é convidado a mover os objetos num caminho que aumenta de complexidade à medida que o jogador avança no jogo.

O jogo foi testado recorrendo a uma amostra de 52 pacientes onde houve um elevado grau de aceitação (HUANG et al., 2016).

PhysioPlay - Jogo direcionado à reestruturação da postura global em indivíduos com escoliose. Em ambiente de jogo, o jogador assume o papel de um robot que tem como tarefa organizar caixas (encomendas). Se a postura do jogador estiver incorreta, a dificuldade em organizar a caixa aumenta, diminuindo a 


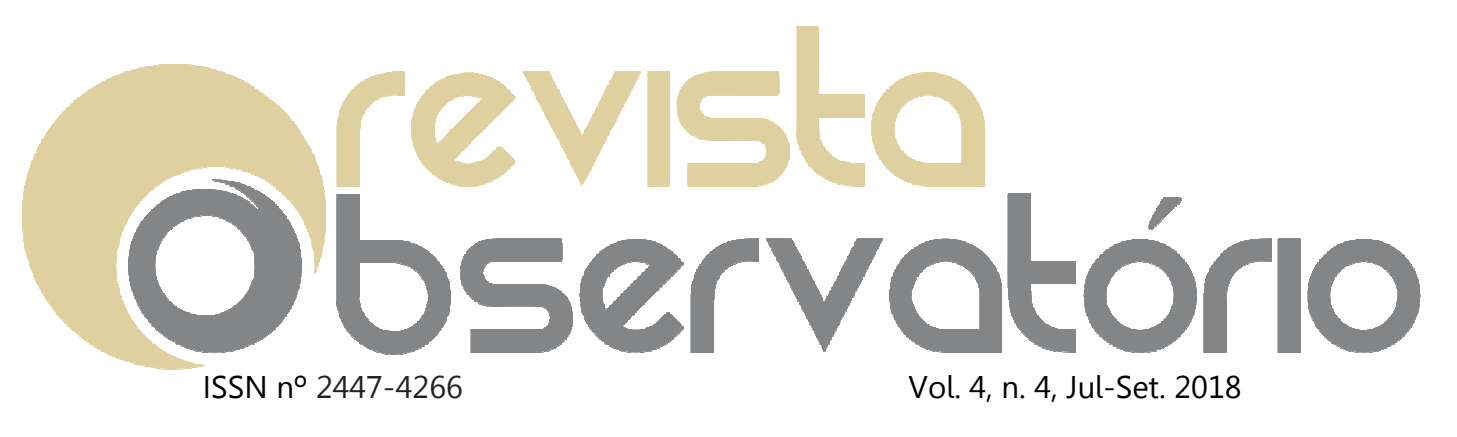

DOI: https://doi.org/10.20873/uft.2447-4266.2018v4n4p46

probabilidade de ser colocada no sítio correto. O jogo está desenhado para PC, sendo que o esqueleto do jogador (a sua postura) é detectado recorrendo a um Kinect (SANTOS; CARVALHO; BRESSAN, 2010).

Physiofun Game - É um jogo para ajudar na reabilitação de doentes vítimas de AVC, servindo de complemento à fisioterapia clássica. Conceptualmente, o jogo está dividido em 6 níveis de dificuldade e possui uma narrativa baseada em episódios históricos relevantes da história da aviação, uma vez que o AVC ocorre predominantemente em indivíduos séniores, uma faixa etária com preferência por narrativas que incluam contextos e factos históricos. Apesar de terem sido conceptualizados 6 níveis de jogo, os autores só implementaram digitalmente o primeiro nível. O primeiro nível de jogo aborda as expectativas iniciais dos seres humanos quando tentaram voar pela primeira vez e se lançavam de torres altas com asas acopladas ao corpo (VELOSO; COSTA; RIBEIRO, 2016). O objetivo do jogo é posicionar uma carroça com palha por baixo da torre de modo a que salve um homem-pássaro.

O jogo é controlado por meio de um wearable (pulseira com sensores de movimento) construído para o efeito (RIBEIRO; VELOSO; COSTA, 2016).

PhysioMate - Gamificação de terapia motora para usuários de cadeira de rodas ou indivíduos com mobilidade reduzida com origens variadas, desde doenças neurodegenerativas, AVC, ou idade avançada. O sistema gamificado tem dois modos, utilizador registado (M1) e utilizador não registado (M2). Em M1, o seu cuidador de saúde planeia uma "rotina de movimentos" e em M2 são disponibilizados um conjunto de movimentos standard pré-definidos. Uma vez escolhida a tarefa, o sistema mostra o movimento que o utilizador deve 


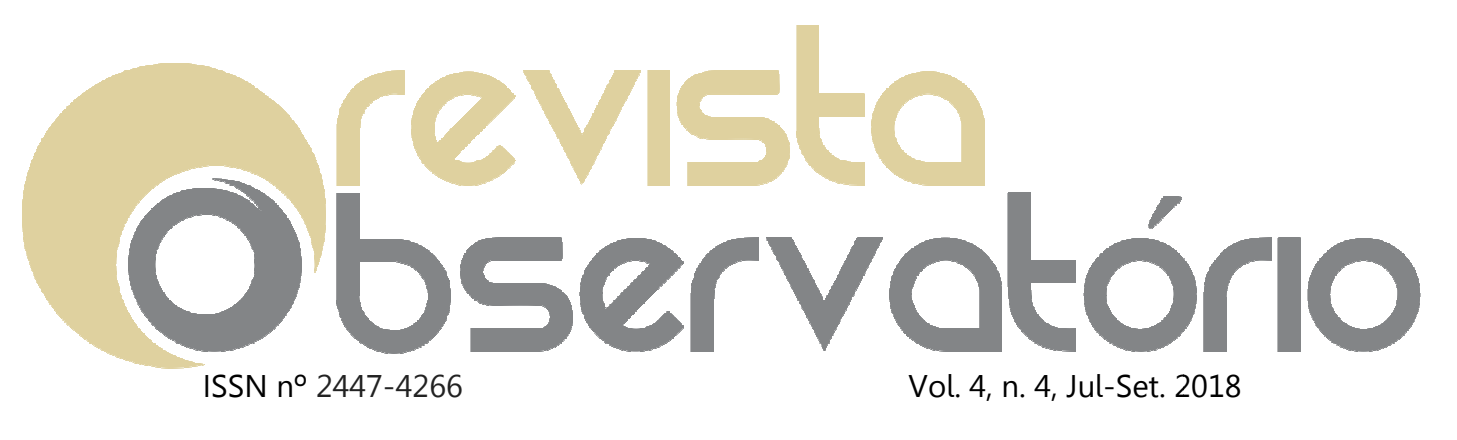

DOI: https://doi.org/10.20873/uft.2447-4266.2018v4n4p46

executar através de uma representação virtual. De seguida, o utilizador executa o movimento e o sistema gera uma pontuação que é tanto mais baixa quanto a diferença entre a execução e a representação virtual disponibilizada. Os exercícios podem incluir atividades de transferência de peso (transferir peso de um lado do corpo para outro), rotação do tronco e alongamentos. O instrumento foi concebido para $P C$, sendo que é utilizado um Kinect para registar os movimentos do utilizador (MADEIRA; COSTA; POSTOLACHE, 2014).

Karate Rehab - Jogo para ajudar no tratamento de problemas associados ao SNC e que possam colocar em causa a mobilidade do jogador. Em ambiente de jogo, o jogador deve executar o movimento de flexão-extensão do ombro, como se estivesse a fazer movimentos de Karaté. Para mediar a interação, o sistema necessita de um Kinect para registar os movimentos do jogador e a técnica de eletroencefalografia (EEG) para medir a atividade cerebral do jogador e, assim, verificar se existem melhorias em zonas cerebrais danificadas (MUNOZ et al., 2014).

EEG é um mecanismo de medida da atividade cerebral que consiste em elétrodos cuidadosamente colocados no escalpe do utilizador e cálculo do potencial elétrico produzido pela atividade neural do cérebro. Esta tecnologia é vestível e pode ser portátil, tendo como vantagem o facto de conseguir um tempo de resposta rápido (na ordem das dezenas ou centenas de milissegundos) (MULLEN et al., 2015).

Touch the Color / Catch the Shape - Dois jogos que pertencem ao mesmo sistema de jogo proposto por ABD LATIF e respectivos co-autores (2014) que visa apoiar a reabilitação de doentes vítimas de AVC. O utilizador tem noção do 


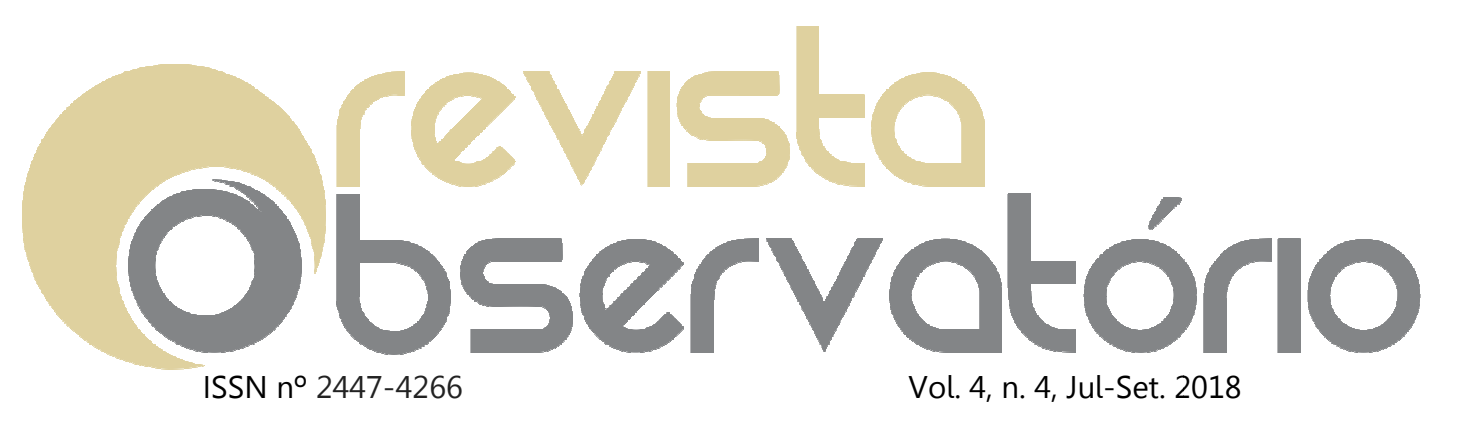

DOI: https://doi.org/10.20873/uft.2447-4266.2018v4n4p46

seu corpo através da representação de um esqueleto que aparece no écran. Numa interação inicial, de habituação ao sistema, o jogador tem que levantar os membros superiores (colocando o corpo em simetria) em amplitudes especificas (de $0^{\circ}$ a $90^{\circ}$ ). No segundo nível de interação, em Touch the colour, o jogador deve posicionar a sua mão em círculos coloridos que aparecem de uma forma aleatória no écran, colocados visualmente no ambiente de interação que é capturado através da câmara do Kinect. Em Catch the Shape, há uma série de figuras geométricas a cair no écran que o jogador deve "apanhar" através de movimentos com os membros superiores. Neste último nível, há uma representação do esqueleto do jogador (à semelhança do que acontece no nível introdutório) e de uma caixa no canto superior em combinação com o ambiente real captado através da câmara. Em ambos os jogos, o sistema de pontuação é semelhante: o jogador recebe mais pontos quanto mais objetos de jogo forem tocados, durante um tempo limitado pelo sistema. O jogo está concebido para PC, sendo necessário um Kinect para detectar o corpo do jogador e seus movimentos (ABD LATIF et al., 2014).

Cognitive Balance - Jogo digital para auxiliar no tratamento pós AVC, onde o jogador desempenha o papel de um Avatar que está a equilibrar-se numa árvore virtual. O objetivo do jogo é tentar equilibrar o avatar movendo o corpo, compensando o peso de cada lado do corpo, movendo as mãos e o tronco, de forma a que a representação virtual da personagem mantenha o equilíbrio. A cada 15 segundos, uma pedra é lançada em direção ao . Neste momento, para se proteger, o utilizador deve estar concentrado na tarefa uma vez que, utilizando EEG, são medidas as suas ondas cerebrais e quanto maior for a concentração, maior é uma esfera criada como forma de proteção do avatar. À 


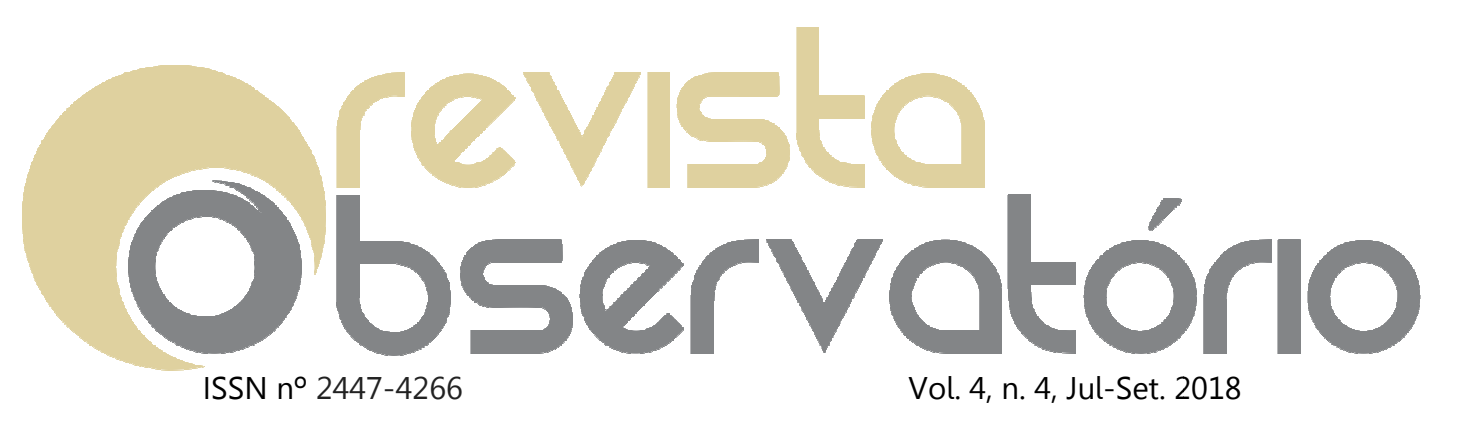

DOI: https://doi.org/10.20873/uft.2447-4266.2018v4n4p46

semelhança do que acontece em outros jogos digitais descritos, os movimentos do jogador são medidos utilizando um Kinect (MUÑOZ; CHAVARRIAGA; LOPEZ, 2014).

Estudo com Kinect - Estudo sobre a viabilidade de um protótipo que utiliza o Kinect para o suporte da reabilitação dos membros superiores em doentes vítimas de AVC. O objetivo do jogo é selecionar imagens que aparecem de forma aleatória numa grelha de 36 células. De forma a não seja muito complicado acertar na imagem inicialmente aparece no écran um quadrado que simboliza a área onde vai aparecer a imagem alvo onde o jogador tem que acertar. Inicialmente a área tem 4 células, mas este quadrado aumenta á medida que o utilizador progride no jogo, sendo que o ultimo nível o jogador não tem ajuda. Cada nível tem uma duração de cerca de 1 e 2 minutos. O jogo foi testado em contexto hospitalar com um paciente (casa dos 40), cujo AVC tinha ocorrido 25 meses antes da experimentação, em que este jogou o jogo todos os dias durante 10 dias consecutivos. O paciente achou a experiência gratificante, sendo que depois de the ser apresentado o jogo apresentava uma maior satisfação com a terapia, no entanto não apresentou melhorias na mobilidade uma vez que para jogar o jogo, o paciente arrastava o braço afetado pelo AVC com o braço saudável (PASTOR; HAYES; BAMBERG, 2012). 


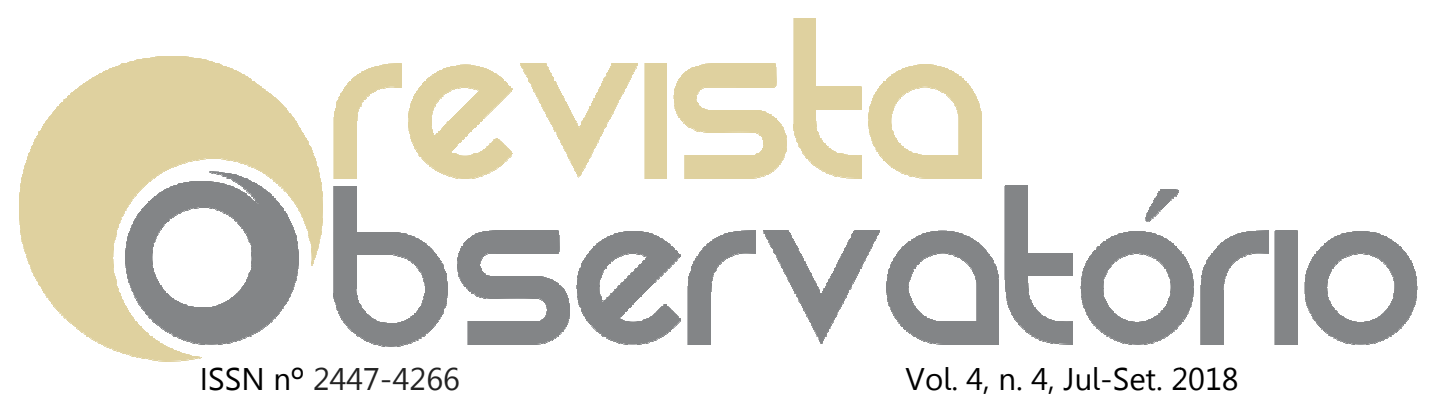

DOI: https://doi.org/10.20873/uft.2447-4266.2018v4n4p46

Tabela 1 - Síntese das características dos jogos digitais analisados

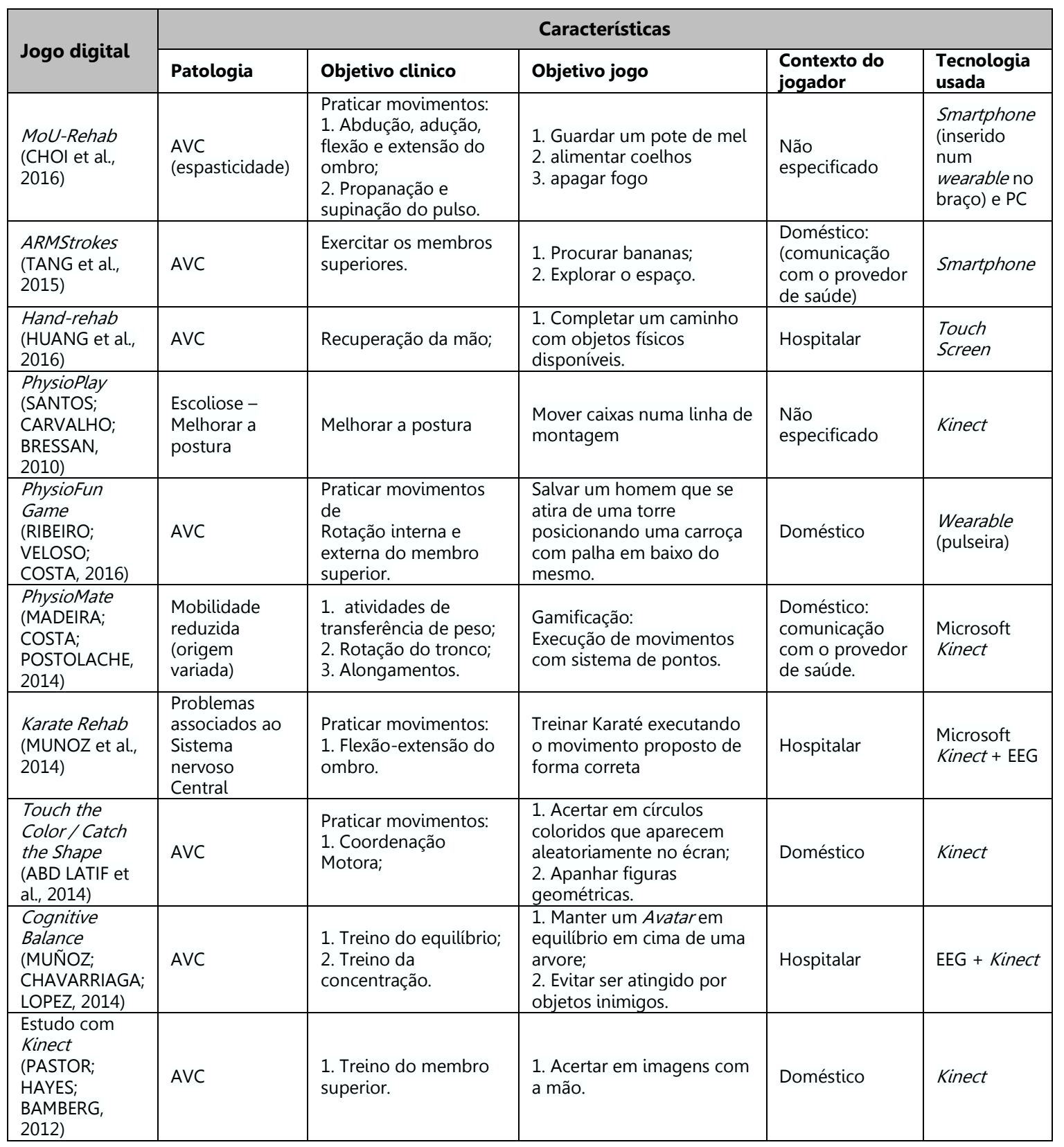




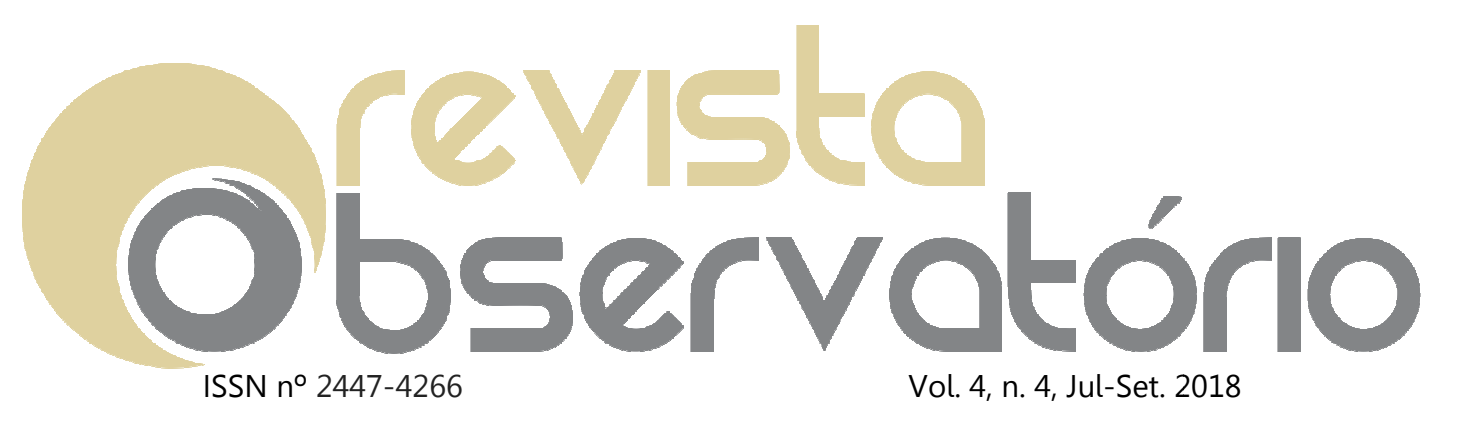

DOI: https://doi.org/10.20873/uft.2447-4266.2018v4n4p46

\section{Análise e discussão dos dados}

De forma a sistematizar a informação recolhida, na Tabela 1 podem ser consultadas as principais características de cada jogo digital analisado segundo a patologia dos pacientes; os objetivos clínicos traçados para a recuperação dos movimentos afetados pela patologia; os objetivos clínicos traçados para desenvolvimento do jogo digital em função da patologia anteriormente identificada; o contexto do jogador está relacionado com ambiente onde o paciente realiza os exercícios propostos - doméstico ou hospitalar. É de salientar o facto de nenhum dos jogos aqui descrito ter sido testado de uma forma prática pelos autores deste artigo, tendo a análise apenas com base na leitura das publicações científicas.

Na seleção dos artigos, seguindo a metodologia descrita na secção de "Introdução" deste artigo, verificou-se que a maioria dos estudos foca-se na sugestão de artefatos tecnológicos que têm como ambição a ajuda do tratamento da mobilidade em indivíduos que sofreram AVC: 7 em 10 estudos analisados (ABD LATIF et al., 2014; CHOI et al., 2016; HUANG et al., 2016; MUNOZ et al., 2014; MUÑOZ; CHAVARRIAGA; LOPEZ, 2014; PASTOR; HAYES; BAMBERG, 2012; RIBEIRO; VELOSO; COSTA, 2016; TANG et al., 2015). Dos restantes estudos, um estudo é dedicado ao tratamento de escoliose, um estudo dedicado à resolução de problemas associados ao SNC (que inclui AVC) (MUNOZ et al., 2014) e um estudo onde se propõe um jogo para a resolução de problemas associados à reposição da mobilidade em geral (MADEIRA; COSTA; POSTOLACHE, 2014).

A preocupação por esta condição de saúde justifica-se pelo facto das doenças cardiovasculares serem predominantes na sociedade ocidental devido aos hábitos de consumo (GBD 2015 DISEASE AND INJURY INCIDENCE AND 


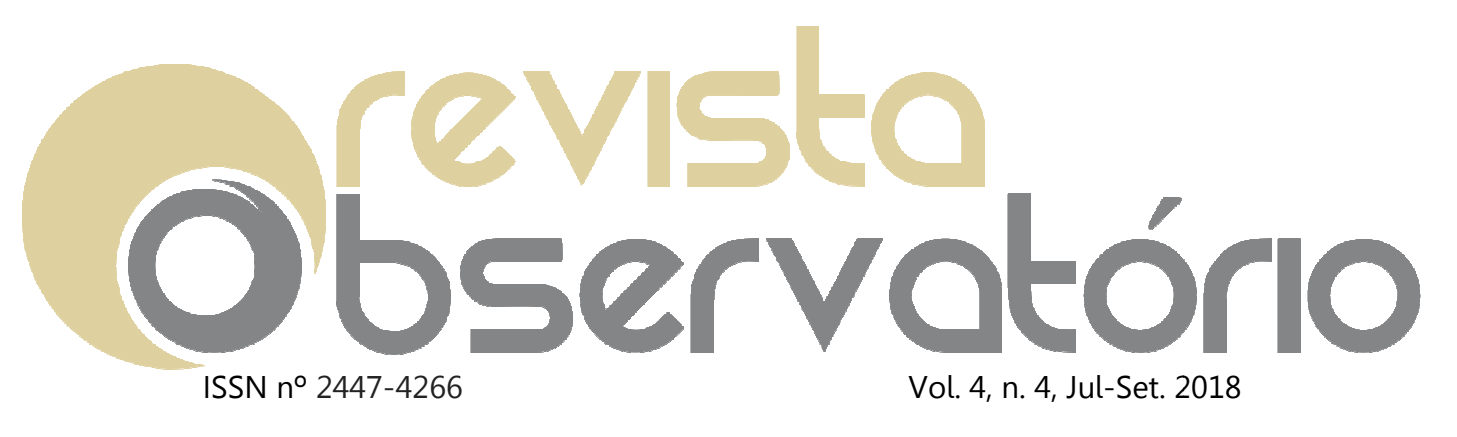

DOI: https://doi.org/10.20873/uft.2447-4266.2018v4n4p46

PREVALENCE COLLABORATORS, 2016a; TRUELSEN; BEGG; MATHERS, 2000) e pelo facto dos doentes que sofrem deste problema terem probabilidades efetivas de recuperação, devido ao fenómeno da plasticidade neural motivada pela prática de exercícios.

A plasticidade neural é a capacidade do cérebro desenvolver novas conexões sinápticas entre neurónios a partir do comportamento e da experiência do indivíduo. Este fenómeno é justificado através de um mecanismo através do qual a estrutura cerebral codifica a experiência e a aprendizagem de novos comportamentos, ou saberes, como resposta a estímulos físicos e/ ou intelectuais (KLEIM; JONES, 2008). Para isto acontecer, o doente deve praticar o máximo possível, os movimentos que quer ver reestabelecidas, uma vez que uma determinada aprendizagem só é fixada no SNC se a experiência ocorrer em número significativo. No caso do AVC, as repetições devem ser na ordem dos milhares para cada tipo de movimento que se perdeu (KLEIM; BARBAY; NUDO, 1998). Uma má monitorização das ações do paciente pode levar a aprendizagens erradas e a padrões de movimentos errados que podem originar problemas em cascata no sistema motor esquelético. Assim, o uso destes jogos não deve nunca dispensar a monitorização de um profissional de saúde especializado (KLEIM; JONES, 2008).

Nas 10 propostas analisadas, 3 delas são jogos para serem jogados em contexto hospitalar (HUANG et al., 2016; MUNOZ et al., 2014), sem nenhuma referência à existência de um sistema ou base de dados responsável por gravar os movimentos dos pacientes, número de derrotas ou número de tentativas para a realização de uma determinada tarefa. Dois dos jogos estudados têm como objetivo exercer um papel ativo no ambiente doméstico do paciente, através da monitorização dos gestos, avanços e recuos de uma forma 


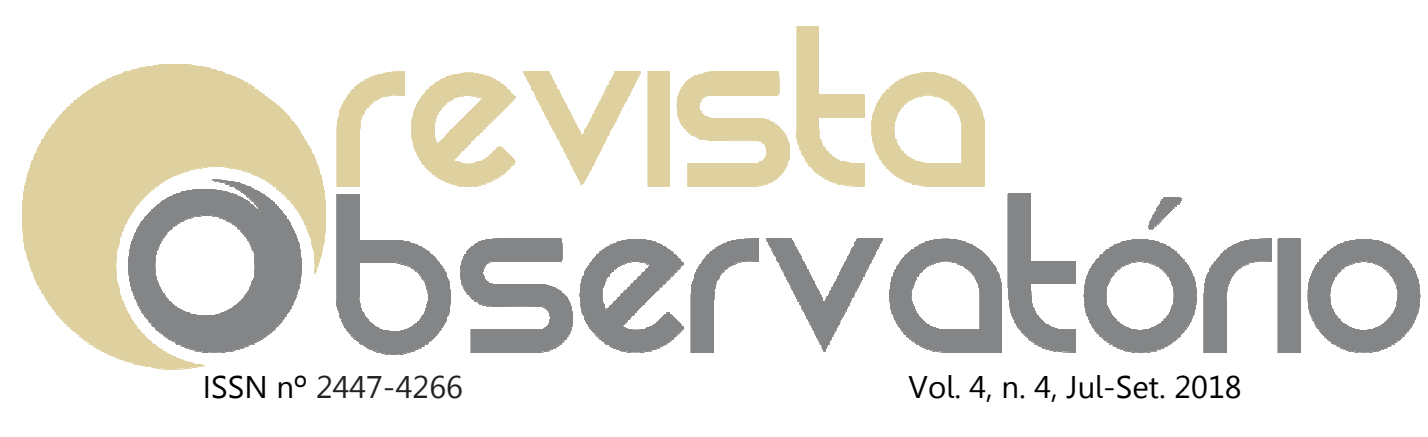

DOI: https://doi.org/10.20873/uft.2447-4266.2018v4n4p46

assíncrona, sendo os únicos estudos a referir que o provedor de saúde poderia desenhar treinos específicos de acordo com as necessidades do paciente (MADEIRA; COSTA; POSTOLACHE, 2014; TANG et al., 2015). Esta característica assume alguma relevância uma vez que cada paciente é um individuo com necessidades e características específicas.

No que diz respeito à forma de interação, todos os jogos recorrem à monitorização de gestos, diferindo no tipo de gestos terapêuticos utilizados para interagir com o ambiente de jogo. Outro fator que difere entre os jogos analisados é o tipo de hardware responsável por recolher informações do ambiente do jogador: dois estudos fazem uso de sensores que existem na maioria dos smartphones (giroscópio e acelerómetro) para monitorizar a posição relativa do membro superior fragilizado do doente ( $\mathrm{CHOI}$ et al., 2016) (TANG et al., 2015). De forma semelhante, mas em vez de smartphone, um dos estudos analisados (RIBEIRO; VELOSO; COSTA, 2016) recorre ao mesmo tipo de sensores incorporados numa pulseira. Este artefato é significativamente mais leve que um smartphone, pelo que pode ser vantajoso para o paciente, principalmente se for um paciente com espasticidade. A solução da pulseira pode também ser uma vantagem se tivermos em consideração o preço do smartphone face ao preço da aquisição sensores de uma forma isolada.

Um dos estudos analisados, em vez de monitorizar diretamente a posição dos membros do paciente, recorre às capacidades multi-toque de um monitor. Esta proposta visa digitalizar um exercício bastante comum em contexto hospitalar, adicionando-lhe uma camada lúdica que consiste no incentivo à superação de desafios e na introdução de um sistema de pontos. Do ponto de vista da monitorização dos movimentos do paciente não se trata de 


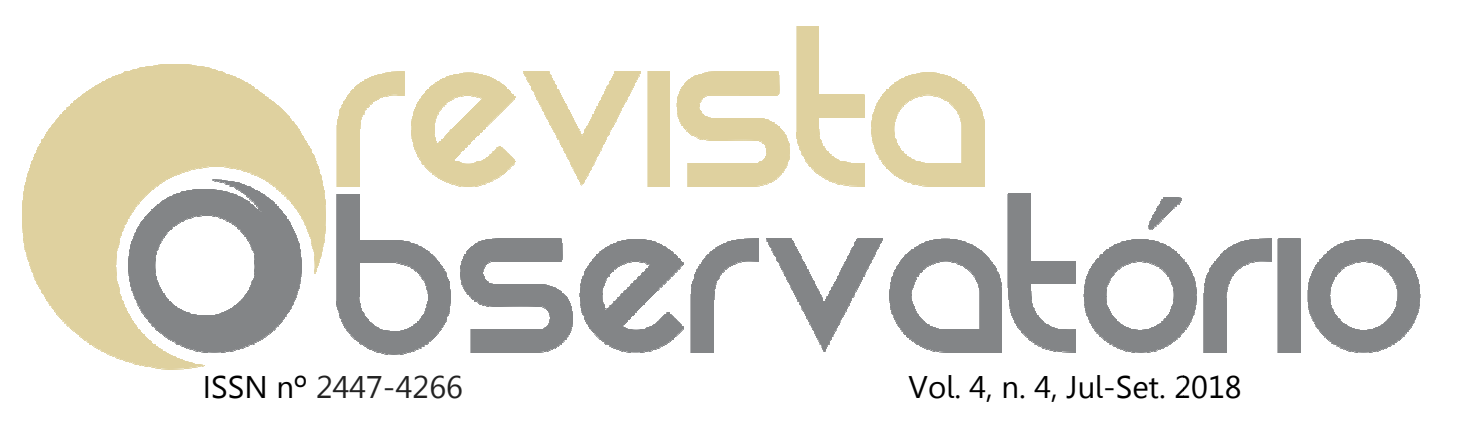

DOI: https://doi.org/10.20873/uft.2447-4266.2018v4n4p46

uma solução eficaz, mas, como o jogo é para ser utilizado em contexto hospitalar, pressupõe-se o acompanhamento de um técnico de saúde.

A maioria dos jogos analisados recorrem ao Kinect para monitorizar os movimentos físicos do paciente. A utilização desta tecnologia justifica-se porque, por um lado é uma ferramenta capaz de monitorizar as principais zonas do corpo humano, por outro, é uma ferramenta amplamente documentada (SANTOS; CARVALHO; BRESSAN, 2010; MADEIRA; COSTA; POSTOLACHE, 2014; MUNOZ et al., 2014; (ABD LATIF et al., 2014; ;MUÑOZ; CHAVARRIAGA; LOPEZ, 2014; (PASTOR; HAYES; BAMBERG, 2012). Dois dos jogos analisados, para além de recorrerem ao Kinect para monitorizaram os movimentos físicos do paciente recorrem a EEG (MUÑOZ; CHAVARRIAGA; LOPEZ, 2014). Apesar do EEG estar longe de se tornar massificado, em parte devido à dificuldade em colocar os elétrodos as áreas corretas do escalpe, esta tecnologia pode ser um bom auxílio para doentes com áreas cerebrais danificadas. Tendo conhecimento da área danificada (de acordo com dados recolhidos previamente através de tecnologias de imagiologia médica) e colocando os elétrodos de EEG na área respetiva, é possível monitorizar de uma forma direta e síncrona os avanços e recuos dos doentes. Para além disso, atualmente é possível monitorizar de uma forma mais ou menos garantida, ondas do tipo P300, libertadas em processos de tomada de decisão, elemento também importante para medir a motivação do paciente.

Tendo em conta os estudos analisados, os jogos digitais para reabilitação física não devem pôr de parte os movimentos de reabilitação da fisioterapia tradicional, e devem ter em conta as características do design de jogos que motivam os jogadores para a prática de jogo, sem excluir a experiência do utilizador e a usabilidade do sistema. Assim sendo, as 


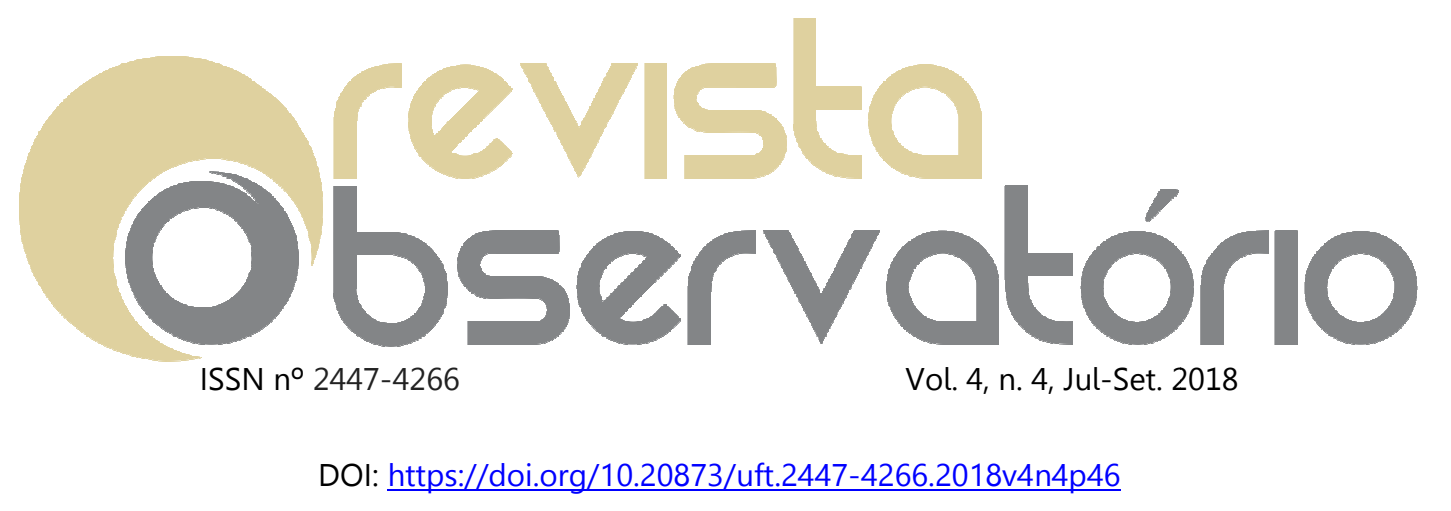

recomendações para o design dos jogos digitais para a reabilitação física abrangem 3 domínios:

1. Domínio do game design:

a. Facultar um ambiente lúdico para a prática de fisioterapia e/ou de terapia física;

b. Oferecer uma narrativa que motive o jogador;

c. Aumento gradual dos níveis de dificuldade do jogos digital à medida que o jogador vai evoluindo no contexto de jogo;

d. Sistema de níveis e/ou checkpoints;

e. Diferentes feedbacks (visual, sonoro, entre outros) em resposta às ações do jogador

2. Domínio fisioterapêutico:

a. Adequar o game design para promover a terapia adequada à patologia paciente;

b. Incluir no game design gestos adequados à(s) patologia(s);

c. Incluir no game design gestos adequados ao(s) diferentes estágios de recuperação do paciente;

3. Domínio da interação:

a. Interação no ambiente jogo digital baseada em gestos fisioterapêuticos;

b. Hardware e software adaptado ao reconhecimento do corpo físico do paciente;

c. Hardware e software user friendly (fácil de montar e usar, com instruções diretas e precisas);

d. Fornecer de um canal de comunicação que possibilite o cuidador de saúde supervisionar o estado e evolução do paciente; 


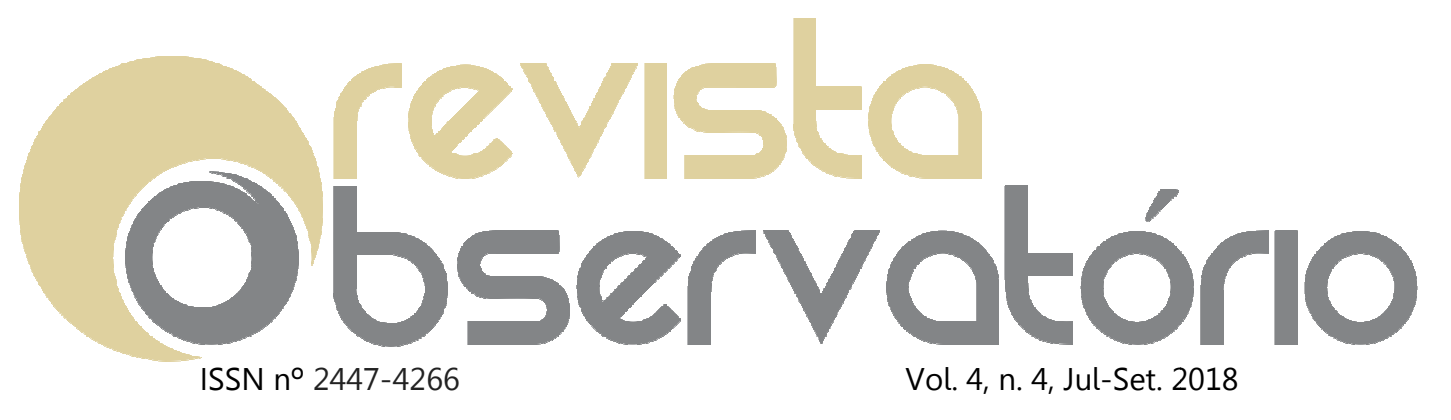

DOI: https://doi.org/10.20873/uft.2447-4266.2018v4n4p46

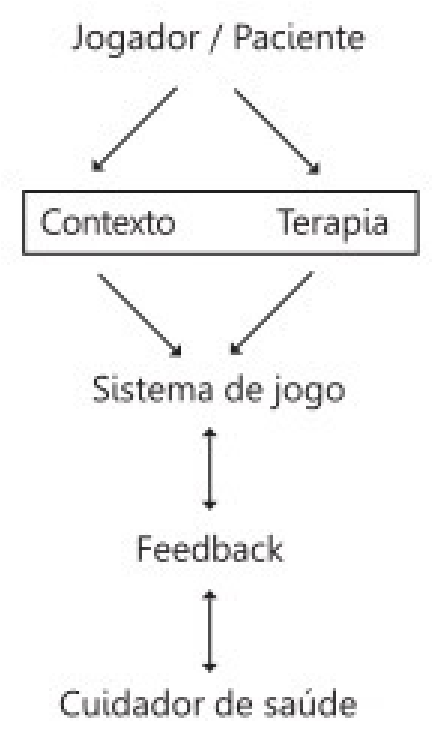

Figura 1 - Resumo das recomendações: as setas representam a interdependência dos conceitos

\section{Considerações finais e trabalho futuro}

Os jogos digitais analisados nesta investigação encontram-se todos em fase de desenvolvimento e nenhum deles existe no seu formato comercial, nem para o público em geral, nem em formato de Demo para o público-alvo para o qual foram desenvolvidas.

Os jogos para a reabilitação física representam ainda desafios elevados de ordem técnica e conceptual: por um lado, as interfaces de interação por gestos, apesar de serem uma realidade ainda estão longe de estar no máximo do potencial no que diz respeito à detecção e processamento de todos os movimentos humanos. Por outro lado, o desenvolvimento de artefatos para motivar seres humanos a levar a cabo uma reabilitação, que na maioria das 


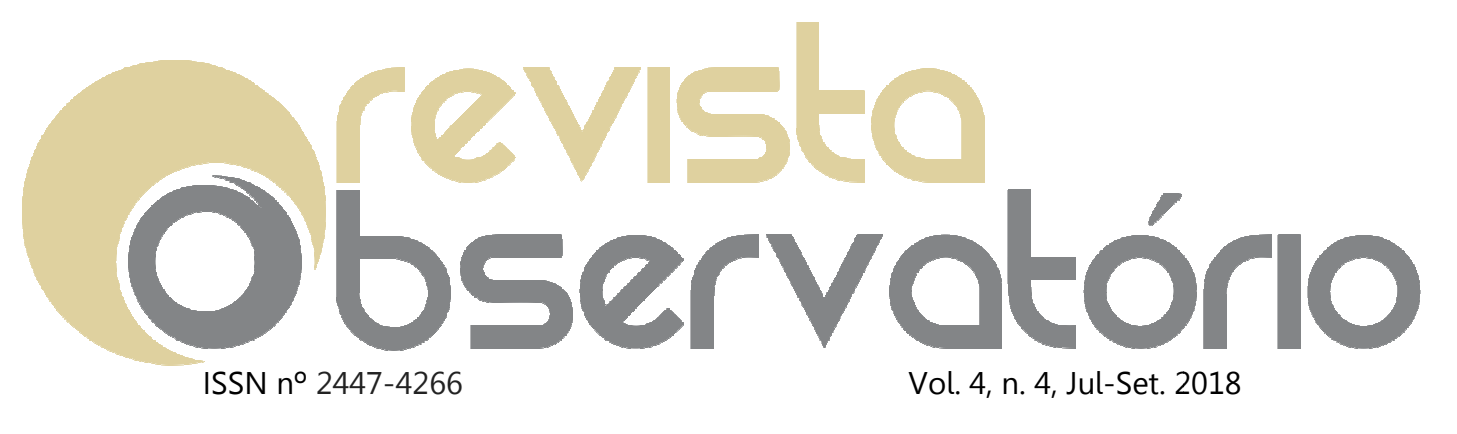

DOI: $\underline{\text { https://doi.org/10.20873/uft.2447-4266.2018v4n4p46 }}$

vezes é extremamente dolorosa tanto do ponto de vista físico como psicológico, não é uma tarefa simples dado o elevado número de variáveis que estão em causa. $O$ desenvolvimento deste tipo de jogos requer o contributo de múltiplas áreas do saber, desde a medicina, a terapia ocupacional, a engenharia ou a psicologia, sendo que a conceptualização e a implementação deste tipo de jogos continuam a representar um desafio e uma oportunidade hoje mais que nunca.

Como trabalho futuro seria relevante repetir a pesquisa aqui feita, incluindo estudos cujo objetivo fosse ajudar na qualidade de vida de doentes com patologias congênitas, estudos esses que ficaram de fora do âmbito deste artigo.

\section{Referências}

$A B D$ LATIF, M. . et al. A gaming-based system for stroke patients physical rehabilitation. 2014 IEEE Conference on Biomedical Engineering and Sciences (IECBES). Anais...IEEE, dez. 2014

ADAMS, E. Fundamentals of Game Design. 2. ed. [s.l.] New Riders, 2013.

ATARI. AGH Museum - Suncom Aerobics Joystick. Disponível em: <https://goo.gl/nEVj7e>. Acesso em: 31 jan. 2017.

BAINBRIDGE, E. et al. The Effects of the Nintendo Wii Fit on CommunityDwelling Older Adults with Perceived Balance Deficits: A Pilot Study. Physical \& Occupational Therapy In Geriatrics, 23 maio 2011.

BONNECHÈRE, B. et al. The use of commercial video games in rehabilitation: a systematic review. International journal of rehabilitation research. Internationale Zeitschrift fur Rehabilitationsforschung. Revue internationale de recherches de readaptation, p. 277-290, 2016. 


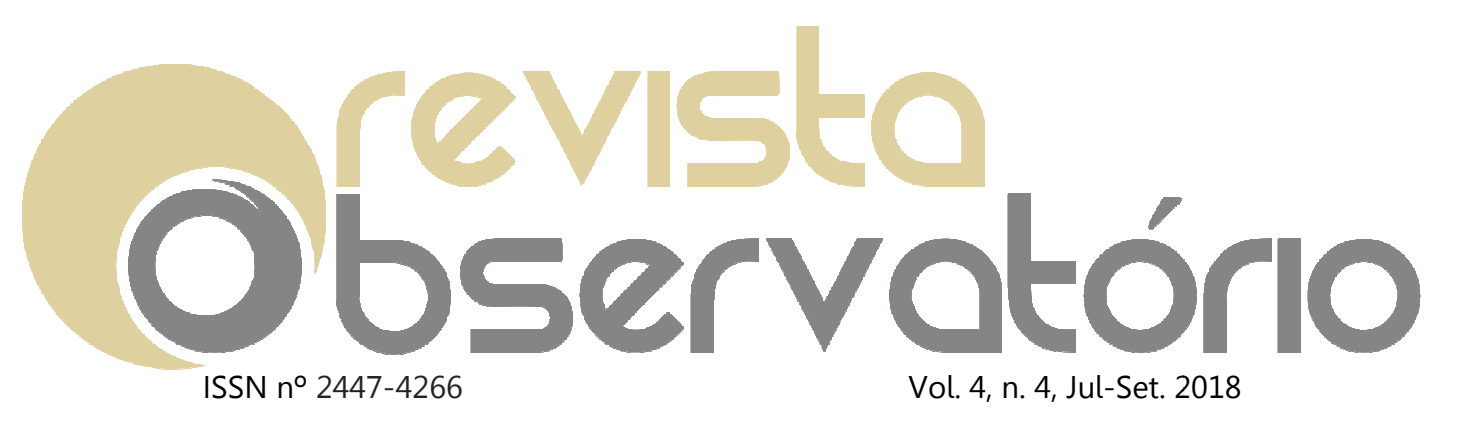

DOI: https://doi.org/10.20873/uft.2447-4266.2018v4n4p46

$\mathrm{CHOI}, \mathrm{Y}$.-H. et al. Mobile game-based virtual reality rehabilitation program for upper limb dysfunction after ischemic stroke. Restorative Neurology and Neuroscience, v. 34, n. 3, p. 455-463, 14 jun. 2016.

CRAWFORD, C. The Art of Computer Game Design. [s.l.] Osborne/McGrawHill, 1984.

CSIKSZENTMIHALYI, M. Flow: The Psychology of Optimal Experience. 1. ed. [s.l.] Harper Perennial Modern Classics, 2008.

DEUTSCH, J. E. et al. Nintendo wii sports and wii fit game analysis, validation, and application to stroke rehabilitation. Topics in stroke rehabilitation, v. 18, n. 6, p. 701-19, 5 jan. 2015.

DICKSTEIN, R. et al. Stroke rehabilitation. Three exercise therapy approaches. Physical therapy, v. 66, n. 8, p. 1233-8, 1 ago. 1986.

FISHER, S. Use of Computers Following Brain Injury. Activities, Adaptation \& Aging, v. 8, n. 1, p. 81-93, 3 fev. 1986.

FULLERTON, T. Game Design Workshop: A Playcentric Approach to Creating Innovative Games. 2. ed. [s.l: s.n.].

GBD 2015 DISEASE AND INJURY INCIDENCE AND PREVALENCE COLLABORATORS. Global, regional, and national incidence, prevalence, and years lived with disability for 310 diseases and injuries, 1990-2015: a systematic analysis for the Global Burden of Disease Study 2015. Lancet (London, England), v. 388, n. 10053, p. 1545-1602, 2016 .

GBD 2015 DISEASE AND INJURY INCIDENCE AND PREVALENCE COLLABORATORS, G. 2015 D. AND I. I. AND P. Global, regional, and national incidence, prevalence, and years lived with disability for 310 diseases and injuries, 1990-2015: a systematic analysis for the Global Burden of Disease Study 2015. Lancet (London, England), v. 388, n. 10053, p. 1545-1602, 2016b.

GRIFFITHS, M. The Therapetic Value of Video Games. Handbook of Computer Game Studies, p. 161-171, 2005.

GRIFFITHS, M.; KUSS, D. J.; ORTIZ DE GORTARI, A. B. Videogames as Therapy: A Review of the Medical and Psychological Literature. In: CRUZ-CUNHA, M. M.; MIRANDA, I. M.; GONÇALVES, P. (Eds.). . Handbook of Research on ICTs and 


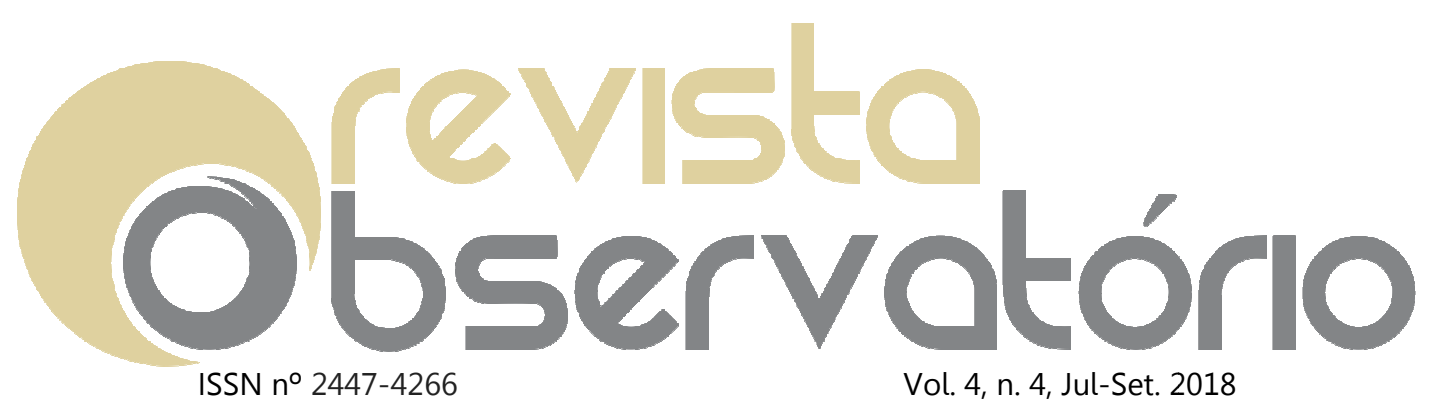

DOI: https://doi.org/10.20873/uft.2447-4266.2018v4n4p46

Management Systems for Improving Efficiency in Healthcare and Social Care. [s.l.] IGI Global, 2013.

HUANG, L.-L. et al. Improvement Design of the Clinical Upper Extremity Rehabilitation Product for Stroke Patients. In: [s.l.] Springer, Cham, 2016. p. 597605.

KHO, M. E. et al. Feasibility and observed safety of interactive video games for physical rehabilitation in the intensive care unit: a case series. Journal of Critical Care, v. 27, n. 2, p. 219.e1-219.e6, abr. 2012.

KLEIM, J. A.; BARBAY, S.; NUDO, R. J. Functional reorganization of the rat motor cortex following motor skill learning. Journal of neurophysiology, v. 80, n. 6, p. 3321-5, dez. 1998.

KLEIM, J. A.; JONES, T. A. Rehabilitation After Brain Damage Principles of Experience-Dependent Neural Plasticity: Implications for Principles of Experience-Dependent Neural Plasticity: Implications for Rehabilitation After Brain Damage. J Speech Lang Hear Res, v. 51, n. February, p. 225-239, 2008. LANG, C. E. et al. Observation of amounts of movement practice provided during stroke rehabilitation. Archives of physical medicine and rehabilitation, v. 90, n. 10, p. 1692-8, out. 2009.

MADEIRA, R. N.; COSTA, L.; POSTOLACHE, O. PhysioMate - Pervasive physical rehabilitation based on NUI and gamification. 2014 International Conference and Exposition on Electrical and Power Engineering (EPE). Anais...IEEE, out. 2014 MAYER, R. E.; MORENO, R. Nine Ways to Reduce Cognitive Load in Multimedia Learning. Educational Psychologist, v. 38, n. 1, p. 43-52, 8 mar. 2003.

MULLEN, T. R. et al. Real-time neuroimaging and cognitive monitoring using wearable dry EEG. IEEE Transactions on Biomedical Engineering, v. 62, n. 11, p. 2553-2567, nov. 2015.

$\mathrm{MUNOZ,} \mathrm{J.} \mathrm{E.} \mathrm{et} \mathrm{al.} \mathrm{BCl}$ and motion capture technologies for rehabilitation based on videogames. IEEE Global Humanitarian Technology Conference (GHTC 2014). Anais...IEEE, out. 2014

MUÑOZ, J. E.; CHAVARRIAGA, R.; LOPEZ, D. S. Application of hybrid $\mathbf{B C l}$ and exergames for balance rehabilitation after stroke. Proceedings of the 11th 


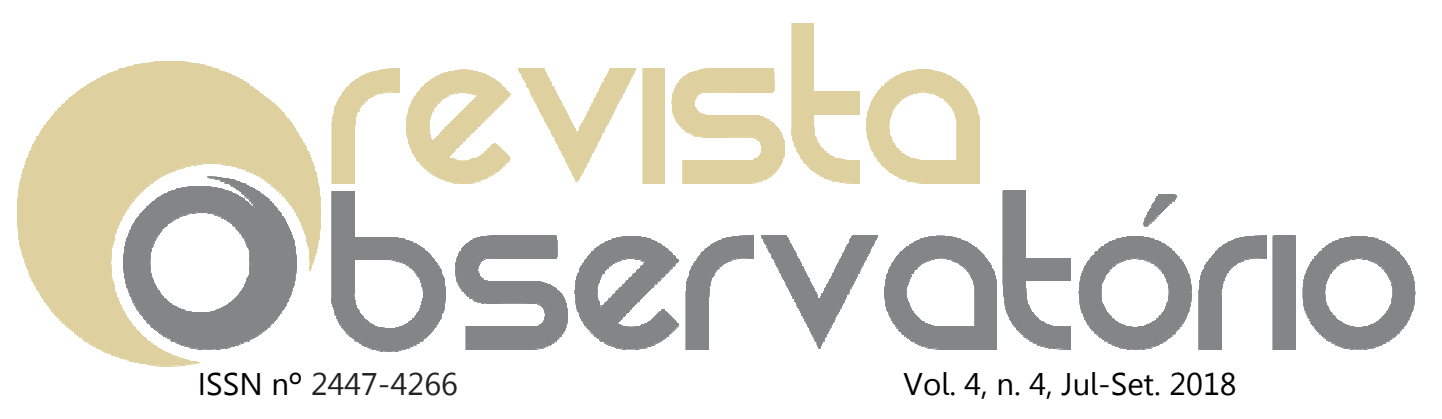

DOI: https://doi.org/10.20873/uft.2447-4266.2018v4n4p46

Conference on Advances in Computer Entertainment Technology - ACE '14. Anais...New York, New York, USA: ACM Press, 2014

NIIZUMI, H. Dance Dance Revolution hits 6.5 million in sales - GameSpot. Disponível em: <https://goo.gl/OLO8oE>. Acesso em: 31 jan. 2017.

O'NEIL, O.; GATZIDIS, C.; SWAIN, I. A State of the Art Survey in the Use of Video Games for Upper Limb Stroke Rehabilitation. In: MA, M.; JAIN, L. C.; ANDERSON, P. (Eds.). . Virtual, Augmented Reality and Serious Games for Healthcare. Intelligent Systems Reference Library. Berlin, Heidelberg: Springer Berlin Heidelberg, 2014. v. 68p. 344-364.

PASTOR, I.; HAYES, H. A.; BAMBERG, S. J. M. A feasibility study of an upper limb rehabilitation system using kinect and computer games. 2012 Annual International Conference of the IEEE Engineering in Medicine and Biology Society. Anais...IEEE, ago. 2012

RIBEIRO, T.; VELOSO, A. I.; COSTA, R. Conceptualization of PhysioFun game: A low-cost videogame for home-based stroke rehabilitation. 2016 1st International Conference on Technology and Innovation in Sports, Health and Wellbeing (TISHW). Anais...IEEE, dez. 2016

RIVERO, T. S.; QUERINO, E. H. G.; STARLING-ALVES, I. Videogame: seu impacto na atenção, percepção e funções executivas. Revista de Neuropsicologia Latinoamericana, v. 4, n. 3, p. 38-52, 2012.

SAFFER, D. Designing Gestural Interfaces: Touchscreens and Interactive Devices. [s.l.] O'Reilly Media, Inc., 2008.

SANTOS, J.; CARVALHO, L.; BRESSAN, P. Physioplay: Um exergame para reabilitação física aplicando a interatividade do Kinect ${ }^{\circledR}$ como biofeedback visual. Lbd.Dcc.Ufmg.Br, p. 2-5, 2010.

SINCLAIR, J.; HINGSTON, P.; MASEK, M. Considerations for the design of exergames. Proceedings of the 5th international conference on Computer graphics and interactive techniques in Australia and Southeast Asia - GRAPHITE '07. Anais...New York, New York, USA: ACM Press, 2007Disponível em: <http://portal.acm.org/citation.cfm?doid $=1321261.1321313>$. Acesso em: 20 jan. 2017 


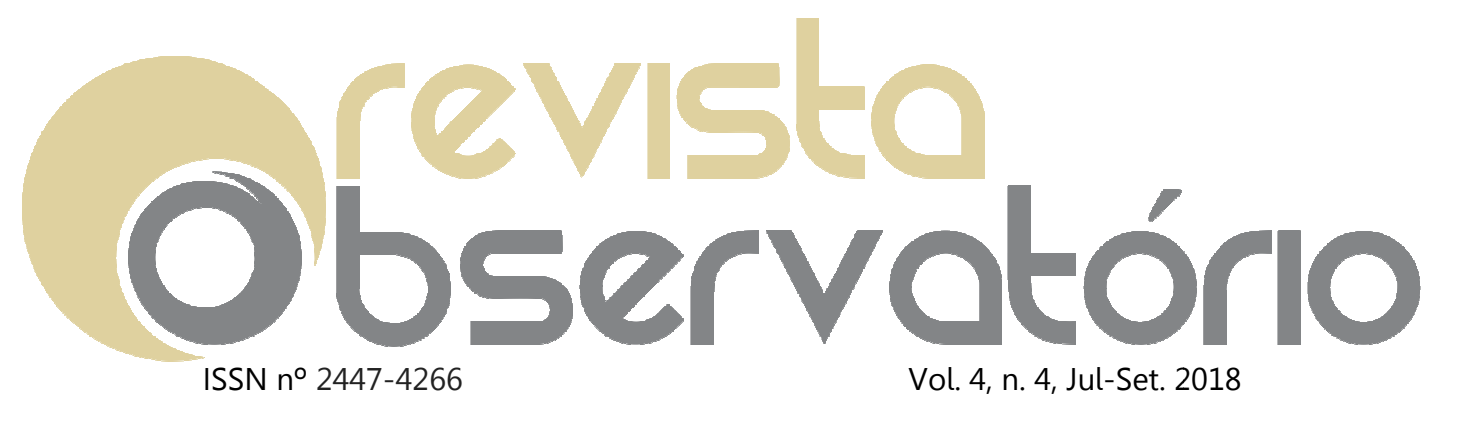

DOI: https://doi.org/10.20873/uft.2447-4266.2018v4n4p46

STRAIT, M.; SCHEUTZ, M. What we can and cannot (yet) do with functional near infrared spectroscopy. Frontiers in Neuroscience, v. 8, p. 117, 23 maio 2014.

TANG, Z. et al. Collaborative Rehabilitation Support System: A Comprehensive Solution for Everyday Rehab. 2015 IEEE International Symposium on Multimedia (ISM). Anais...IEEE, dez. 2015

TRUELSEN, T.; BEGG, S.; MATHERS, C. The global burden of cerebrovascular disease. 2000.

VELOSO, A. I.; COSTA, L.; RIBEIRO, T. JOGOS DIGITAIS NA PROMOÇÃO DA SAÚDE: DESAFIOS E TENDÊNCIAS. Revista da FAEEBA - Educação e Contemporaneidade, v. 25, n. 46, 2016.

WORLD HEALTH ORGANIZATION. WHO | Physical Activity. Disponível em: $<$ https://goo.gl/YTqibq>. Acesso em: 25 ago. 2017.

YANG, S. Defining Exergames \& Exergaming. Proceedings of Meaningful Play 2010, p. 1-17, 2010. 